Universidad de Lima

Facultad de Comunicación

Carrera de Comunicación

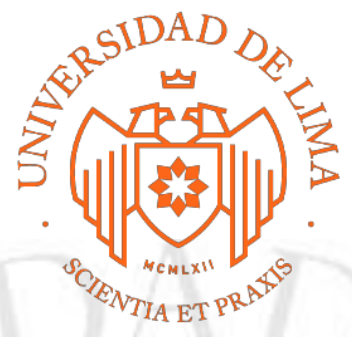

\title{
LANZAMIENTO DE CONDOMINIO VILLA PANAMERICANOS
}

Trabajo de Suficiencia Profesional para optar el Título Profesional de Licenciado en

Comunicación

Sandra Maria Quispe Huayhualla

Código 20052035

Grace Sol María Soto Cáceres

Código 20051124

Lima - Perú

Setiembre de 2019 


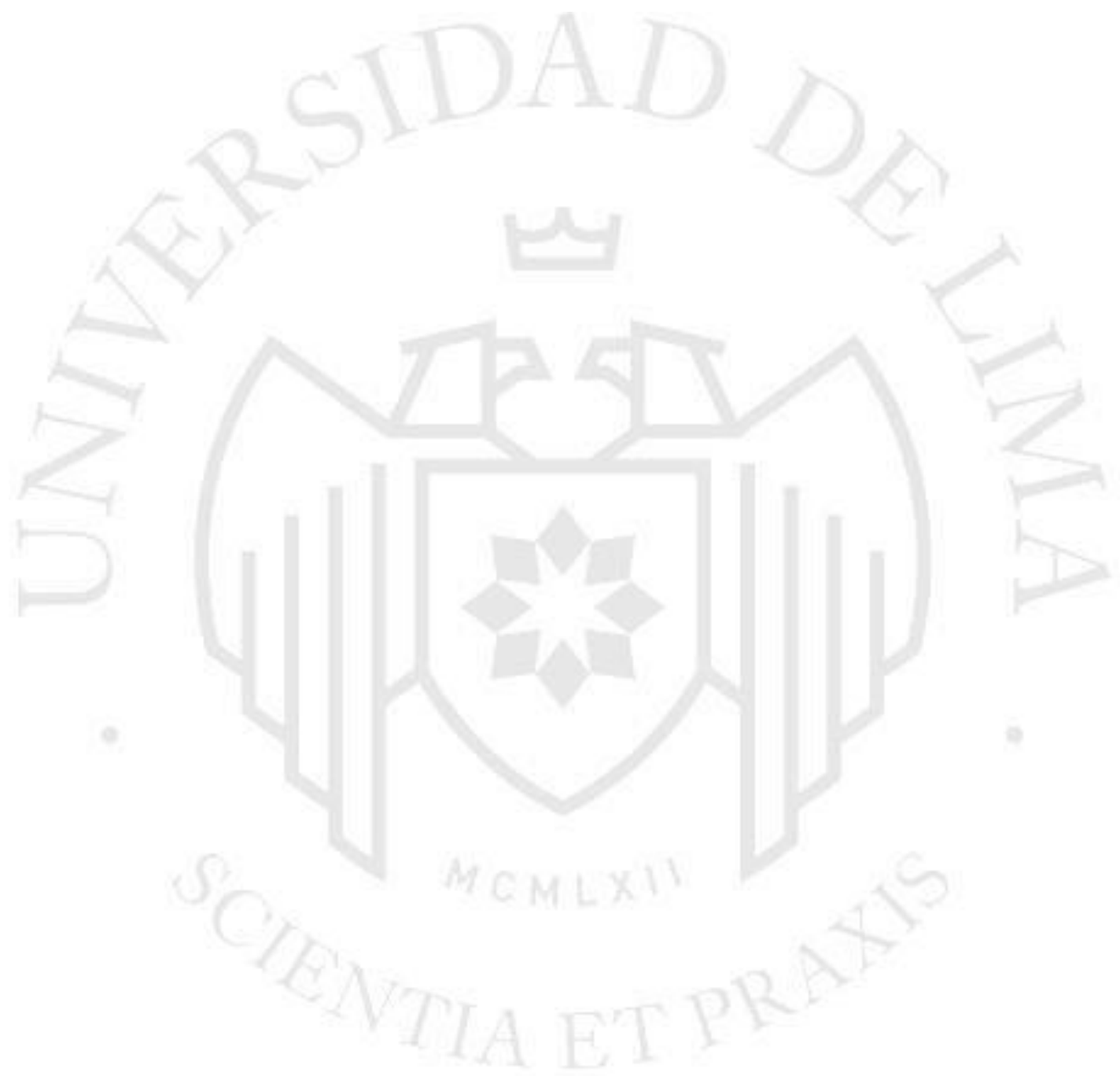




\section{LANZAMIENTO DEL CONDOMINIO VILLA PANAMERICANOS}




\section{RESUMEN}

En este trabajo desarrollaremos nuestra propuesta para el plan de comunicación del Condominio Villa de Atletas, mediante una campaña de 6 meses durante el año 2020. 


\section{ÍNDICE}

\section{- CONTEXTO}

\subsection{Análisis de la situación externa}

1.1.1.Análisis Político

1.1.2. Análisis Económico

1.1.3. Análisis Social

1.1.4. Análisis Tecnológico

1.1.5. Análisis Ecológico

\subsection{Análisis interno}

1.2.1. Villa de Atletas

1.2.2. Fondo Mivivienda

1.2.3. Juegos Panamericanos y Parapanamericanos Lima 2019

\subsection{Desarrollo del Mercado Inmobiliario}

\subsection{Análisis de la competencia}

\section{ANÁLISIS DEL PÚBLICO OBJETIVO}

2.1. Análisis cuantitativo

2.2. Entrevistas a profundidad

\section{DIÁGNOSTICO}

3.1. Análisis FODA

3.2. Segmentación

3.3. Buyer persona

3.4. Emphaty Map

\section{OBJETIVOS}

4.1. Objetivos de Marketing

4.2. Objetivos de Comunicación

\section{IDENTIDAD DE MARCA}

5.1. Nombre

5.2. Posicionamiento

5.3. Ventaja diferencial

5.4. Reason why

5.5. Personalidad de la marca

5.7. Visión 
5.8. Misión

5.9. Valores

6. IDENTIDAD VISUAL

6.1. Logo

6.2. Manual de Logo

7. ESTRATEGIA CREATIVA

7.1. Concepto creativo

7.2. Tono de la comunicación

8. PLAN DE MEDIOS

8.1. Radio

8.2. Prensa

8.3. $\mathrm{OOH}$

8.4. BTL

8.5. Digital

8.6. Relaciones Públicas

9. CONCLUSIONES

10. RECOMENDACIONES

11. REFERENCIAS

12. ANEXOS 


\section{CONTEXTO}

Para mejor entendimiento del contexto actual consideramos importante dividir el análisis externo y el análisis interno.

\subsection{Análisis de la situación externa}

\subsubsection{Análisis Político}

Es importante precisar que el Estado con un fin de promover la compra de viviendas, durante el mes de mayo del 2019, promulgó la Ley $\mathrm{N}^{\text {o }} 30952$ de "Bono de Arrendamiento" con el fin de apoyar a las personas de 18 a 40 años de escasos recursos que deseen alquilar una vivienda con un monto menor de $S / 1500$, quienes serán beneficiadas, ya que un porcentaje del monto que paguen será destinado a formar parte de un ahorro para el pago de la cuota inicial de una vivienda.

Por otro lado, en el aspecto político es importante mencionar la aprobación de la Ley $\mathrm{N}^{\circ} 30949$ que establece el reconocimiento de los atletas peruanos que obtengan alguna medalla en los Juegos Panamericanos y Parapamericanos Lima 2019, cediéndoles un departamento del proyecto Villa de Atletas.

\subsubsection{Análisis Económico}

Según la Asociación de Desarrolladores Inmobiliarios del Perú (ADI Perú) al hacer una comparación de la demanda de créditos hipotecarios del primer semestre del 2019 versus el primer semestre del 2018, se percibe que hubo un aumento del $18 \%$ que hizo que las tasas de interés disminuyeran. Este panorama es óptimo para la categoría, ya que viene recuperándose de una caída significativa presentada en los últimos años.

Por otro lado, los créditos de Fondo Mivivienda ascendieron a 2,679, representando el 45\% más con respecto al año anterior, número que no se veía desde el 2014.

"Esto demuestra la tendencia creciente de los créditos Mivivienda que abarcan los programas de Techo Propio, Nuevo Crédito Mivivienda y Mivivienda Verde. Este año, proyectamos entregar entre $20 \%$ y $25 \%$ de 
créditos más que el año pasado y así alcanzar más de 11 mil créditos. El 2018, tuvimos más de 9 mil”, indicó el ministro Bruce (Diario Gestión)

Así mismo, actualmente, hay 155 proyectos a nivel nacional con 41, 083 viviendas disponibles que cuentan con Bono Verde, de las cuales se pueden beneficiar 993 familias.

\subsubsection{Análisis Social}

En la última Feria Nexo Inmobiliario, realizada del 12 al 15 de setiembre del presente año. Se presentaron 353 proyectos con un promedio de 20,000 viviendas ofertadas, donde la novedad fue la creciente oferta de "minidepartamentos" con un tamaño menor a $40 \mathrm{~m} 2$.

\section{UNIDADES EN OFERTA POR RANGO DE ÁREAS}

(Solo Lima y Callao y Departamentos)

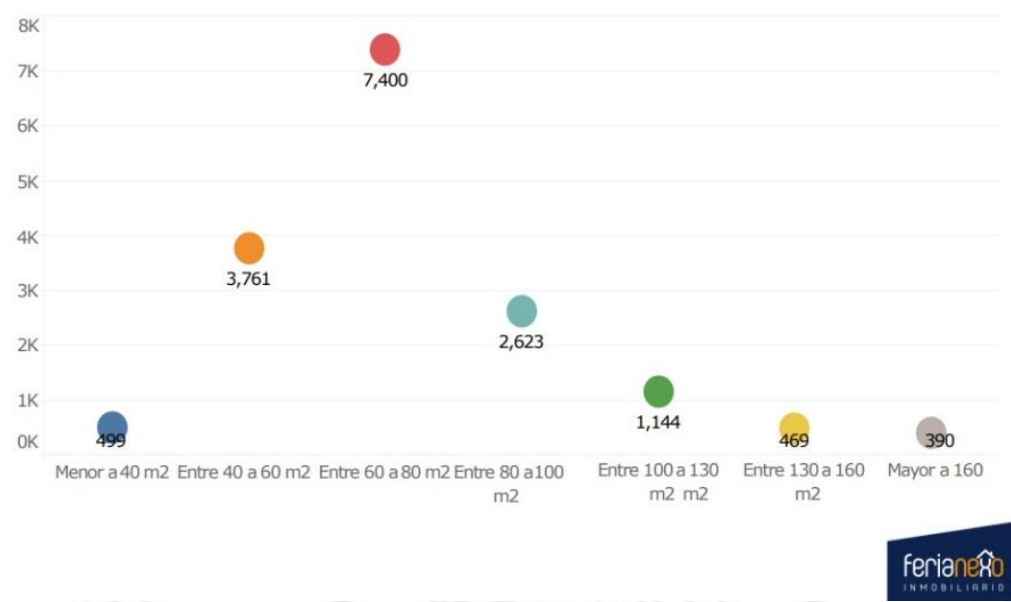

Figura 1: Unidades de oferta por rango de área. Fuente: Nexo Inmobiliario

Si bien esto favorece a la población porque la oferta se va adecuando a la posibilidad económica de las personas, es importante tener en cuenta que en México, Argelia Aragón, una docente investigador de la Universidad Autónoma de Durango afirmó que las viviendas con menos de $45 \mathrm{~m} 2$ generan condiciones de violencia y carencia del sentido de pertenencia. 
"Los hogares, al ser tan pequeños, se vuelven en un centro de estrés común, además de que promueven la exclusión social, es decir, no quieres estar en casa pues todo se escucha como gritos, calor e incluso lesiones superficiales de la piel por lo reducido"

Por otro lado, según los gremios inmobiliarios, la proyección de ventas de viviendas nuevas se aproxima a 16,000 durante el año 2019. Teniendo como premisa que la mayor parte de las ventas se da en la etapa de planos. Por ello la Asociación Peruana de Empresas de Seguros (Apeseg) busca impulsar la obligación de tener un seguro para indemnizar a las personas que adelantaron el pago de su vivienda y la constructora o inmobiliaria no cumple. De esta manera se busca proteger al consumidor y formalizar el rubro.

\subsubsection{Análisis Tecnológico}

Actualmente, las empresas constructoras de viviendas han empezado a darse cuenta de la potencial de la tecnología y han comenzado aprovecharla, no solo por la eficiencia y la productividad durante el proceso, sino para darle valor agregado al producto final.

Es por ello que al hablar de tecnología en la construcción de viviendas, inevitablemente se relaciona a seguridad y sostenibilidad. Para la seguridad es importante mencionar que Lima demanda tecnología de mecanismos que atenúen los movimientos telúricos, es más importante desarrollarlos en edificios de zonas de riesgos o en estructuras públicas como hospitales y colegios. Por otro lado para la sostenibilidad, se está empezando a utilizar cementos bajos en carbono y otros, con el fin que las viviendas protejan a sus habitantes de las bajas temperaturas.

\subsubsection{Análisis Ecológico}

En la actualidad, estamos viviendo una tendencia de mayor responsabilidad con el medio ambiente, la acción más reciente es la Ley que regula el uso de plásticos desechables y envases descartables, que ayuda a que las personas tomen conciencia del buen cuidado del medio ambiente. 
En este sentido, en el sector inmobiliario y construcción, el Perú está destinando un total de 150 millones para la continuidad de proyectos inmobiliarios con características proambientales (Diario Gestión 2019). Una de las primeras iniciativas fue el sistema de Bono Mivivienda Verde que consta de un descuento del 3\% al 4\% del valor de una vivienda y beneficia enteramente al comprador del inmueble.

\section{¿Cómo funciona?}

El Fondo MIVIVIENDA otorga el Bono Mivivienda Verde como un porcentaje ( $3 \%$ o $4 \%$ ) del valor de financiamiento según el grado de sostenibilidad para la adquisición de una vivienda verde en un proyecto certificado.
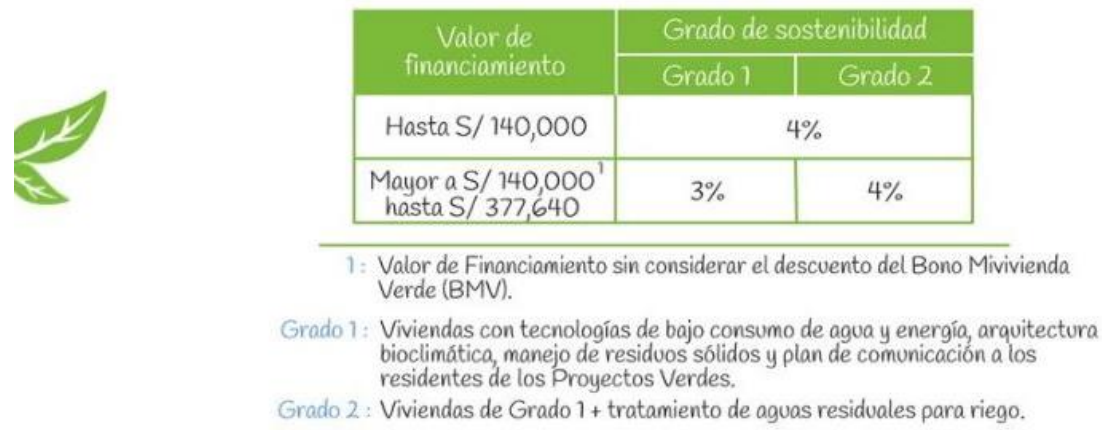

Figura 2: ¿Cómo funciona Bono Mivivienda Verde de Fondo Mivivienda? Fuente: Fondo Mivivienda

Se ha previsto que para el 2020 los proyectos inmobiliarios tendrán la obligación de contar con tecnología ecosostenible y podrán calificar para poder otorgar el Bono Verde. Así mismo, se planea incorporar más grados que conlleven a que los inmuebles ofrezcan un sistema de reutilización de aguas grises y el uso de paneles solares para la iluminación de áreas comunes (Gestión, 2019).

\subsection{Análisis interno}

\subsubsection{Villa de Atletas}

Es un complejo habitacional ubicado en Villa el Salvador, abarca una zona de 44 hectáreas, el área construida cuenta con 7 torres de 19 y 20 pisos que hacen un total de 1096 departamentos de 70 a $75 \mathrm{~m} 2$.

Los departamentos están equipados con 3 dormitorios, sala, comedor, cocina y dos baños.

El diseño del conjunto habitacional tiene facilidades desde el ingreso, puesto que fue diseñado pensando en los deportistas de los Parapanamericanos, pasillos de libre movimiento con silla de ruedas para los 12 primeros pisos. Además algunas zonas esta equipadas con un sistema de lectura braille. 
Todas las torres cuentan con dos núcleos de ascensores que contienen 4 elevadores de medidas 1900 x $1500 \mathrm{~m} 2$ con capacidad de 18 personas, espacio suficientemente amplio para el tránsito de personas con discapacidad. Por primera vez en nuestro país se realizó un estudio de tráfico para transporte de personas con capacidades limitadas, cumpliendo las normas solicitadas para este evento especial. Los ascensores están equipados con espejos en los paños posteriores para un retroceso eficaz. Se ha usado una tecnología muy novedosa con motores gearless de imanes permanentes sin necesidad de engranajes, estos generan un bajo consumo de electricidad y cuentan con sistema de rescate automático.

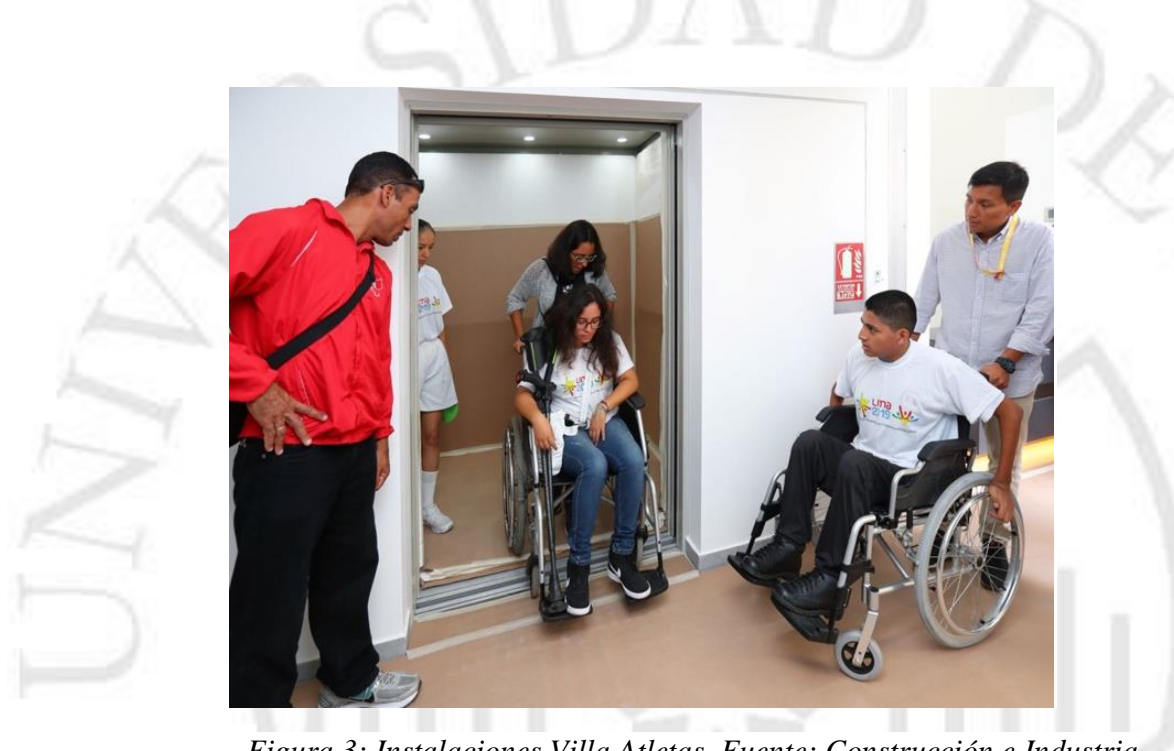

Figura 3: Instalaciones Villa Atletas. Fuente: Construcción e Industria

Las obras complementarias a los departamentos, son los zonas de esparcimiento; pista de jogging de $1 \mathrm{~km}$ que bordea el condominio, canchas multideportivas y pista de ciclismo. Además los Clubhouses que constan de 12 edificaciones para actividades recreativas.

Otro de los beneficios más importantes del condominio es que cumple con la certificación de Bono Mivivienda Verde grado 2, lo que hace al comprador acreedor de un bono del $4 \%$ sobre el precio final del departamento. Lo más importante es que cada comprador está contribuyendo con el medio ambiente al adquirir un departamento que cuenta con mecanismos de última tecnología para el ahorro en el consumo de servicios; iluminación LED y griferías con controladores de flujos. El riego de áreas verdes se hará sin usar la red pública porque se reutilizará las aguas grises de lavatorios y duchas previamente filtradas en una planta propia de tratamiento. 
El precio de los departamentos es de S/ 186,000.00 soles y las facilidades de pago son las siguientes:

\section{-Crédito Fondo Mivivienda \\ -Bono Mivivienda Verde}

La cuota mínima es del 10\%, 18,600 soles, bono del buen pagador que significa un monto 13,000 soles, más el Bono Mivivienda Verde de 5,938.46 soles, quedaría un total a pagar de $148,461.54$

\subsubsection{Fondo Mivivienda}

Crédito hipotecario financiado por el Fondo Mivivienda y canalizado a través de las entidades financieras intermediarias, se puede usar para comprar una vivienda, construir terrenos propios, aires independizados o mejorar tu propia vivienda. Los financiamientos para viviendas están entre S/ 58,800 a S/ 419,600 con un plazo de 5 a 20 años como máximo. Los beneficios que presenta acceder a este crédito son; los bonos, entre ellos Bono del Buen Pagador, Mivivienda Verde y el premio al Buen Pagador, esto se complementa a la cuota inicial. El financiamiento es hasta el $90 \%$ del valor total, la cuota de pago siempre será la misma y se puede realizar prepagos sin penalidades.

¿Cúales son los requisitos que se debe cumplir para acceder al crédito? Los requisitos principales es ser mayor de edad, estar previamente calificado por la entidad financiera asociada, no tener ningún crédito pendiente con el Fondo Mivivienda, no tener otra propiedad o ser copropietario de otra vivienda a nivel nacional, ser residente peruano o peruano residiendo en el extranjero. El aporte mínimo es del 10\% y máximo del $30 \%$ del valor total de la vivienda.

Con respecto al Bono Mivivienda Verde al que califica el conjunto habitacional Villa de Atletas, tiene dos grados que representan el 3\% para el grado 1 y $4 \%$ para el grado 2. Este bono es otorgado a personas que acceden a este crédito Fondo Mivivienda y deciden adquirir una vivienda verde, con este Bono Mivivienda Verde se incentiva y promueve a que la población decida adquirir una vivienda que aporte con el cuidado del medio ambiente, reduciendo los consumos y reciclando de forma correcta los 
residuos. Este bono se calculará descontando el $4 \%$ del valor total de la vivienda, en el caso de grado 2 (importe total de la vivienda entre 1.04\%, multiplicado por 0.04). Los requisitos son contar con la calificación al crédito Fondo Mivivienda, que el comprador o conyugue e hijos menores de edad no tengan otra propiedad y no haber recibido antes Bono Mivivienda Verde.

\subsubsection{Juegos Panamericanos y Parapanamericanos Lima 2019}

El Perú fue por primera vez sede de los juegos Panamericanos este año 2019, dieron inicio el 26 de Julio hasta el 11 de Agosto. Convocó a un gran número de atletas de más de 41 países, reuniendo a 6700 atletas, los cuales participaron en 39 deportes y más de 60 disciplinas.

El evento tuvo un alcance internacional, lo cual nos dio los beneficios de ser expuestos antes los ojos del mundo, fomentando lo nuestro, el turismo y generando beneficios en nuestra economía local, incentivando cada vez más la importancia y el gusto por el deporte. Las competencias estuvieron acompañadas de ceremonias en 14 distritos de Lima y Callao.

Nuestro país se unió para apoyar a la realización de este evento, más de 18 mil voluntarios participaron como anfitriones, también músicos y artistas locales sumaron a las presentaciones entre ellos; Vania Masías, Lucho Quequezana, Gianmarco, Bareto entre otros.

El logotipo fue fruto de un concurso lanzado el año 2014 y el ganador fue el logo de los tres pistilos representando las tres américas. Se escogió a la mascota representativa, también fruto de un concurso donde ganó Cuchimilco, la flor de Amancaes, finalmente la mascota quedó con el nombre de Milco.

La inversión para ambos eventos Panamericanos y Parapanamericanos fue de 1200 millones de dólares que se distribuyeron en 470 millones de dólares en infraestructura, 180 millones de dólares para la Villa Panamericana y 430 millones de dólares en gastos de organización. Se establecieron 21 sedes e instalaciones en total, ubicadas en 14 distritos de Lima y el departamento de Ica. 
¿Pero qué legado nos deja los Juegos Panamericanos y Parapanamericanos? Ahora nuestra capital cuenta con infraestructuras deportivas de primera categoría, a esto se suma la modernización de la Villa Deportiva Nacional (Videna), el Velódromo techado y la escuela de Equitación. Se espera que las mejoras de las infraestructuras deportivas ayuden a nuestros deportistas a mejorar su competitividad en eventos internacionales.

La infraestructura que se edificó para albergar a los deportistas será vendida, 1096 departamentos en total por medio del programa Mivivienda.

En nuestra ciudad se construyeron 200,000 metros cuadrados de pistas y 130,000 de veredas. La estimación para la creación de puestos de trabajo es 500,000 que serían contratados para el mantenimiento y obras.

Por otro lado el beneficio de haber estado en transmisión internacional fortalece nuestra imagen en el exterior como destino turístico, en las ceremonias se enfatizó nuestra cultura artística y costumbres. El presidente de la Cámara Nacional de Turismo, Carlos Canales, señaló que este despliegue ayudará a superar los cinco millones de turistas extranjeros para el 2020.

\subsection{Desarrollo del Mercado Inmobiliario}

En este año 2019 el sector inmobiliario persiste con una carencia entre oferta y demanda de viviendas, según cifras oficiales el interés de adquirir una vivienda es superior a 15,000 y la oferta anual solo es de 25,000. El gerente inmobiliario del Banco BBVA pronosticó que este año puede batir un record en ventas de viviendas porque se han sumado programas de financiamiento de inmuebles, creadas pensando en los diferentes perfiles sociales tales como; Programa Techo Propio, Mivivienda y Mivivienda Verde.

Se pronostica también que el metro cuadrado en Lima tendrá un aumento en el precio de $8 \%$ al cierre de este año 
"Lima es un mercado con muchísima demanda inmobiliaria, se estima que hay 190,000 familias que pueden adquirir viviendas solo en esta ciudad, mientras que hay una oferta constante de 20,000 unidades al mes. Esta demanda debería originar este incremento de precios", precisó Diego Abarca, gerente comercial de Paz Centenario.

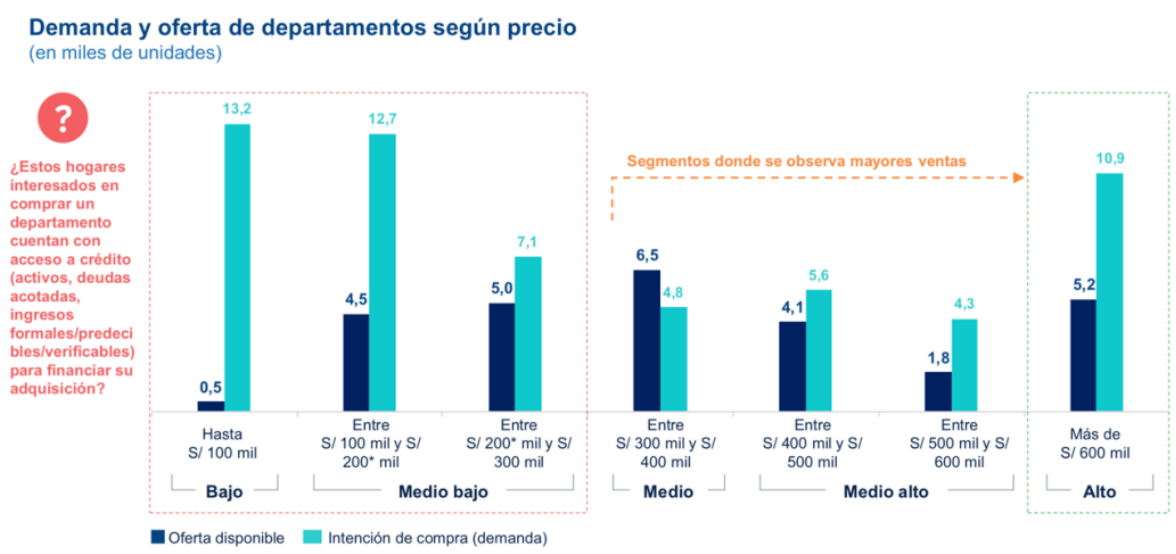

Figura 4: Demanda de oferta de departamentos según precio. Fuente: Perú, Mercado de viviendas nuevas y oficinas prime en Lima Metropolitana.

Este primer semestre del 2019 el incremento en ventas ha sido del $15 \%$ y se espera que el año cierre en 16.5 mil - 17 mil unidades de viviendas vendidas.

El aumento del empleo formal y capacidad adquisitiva hace que cada vez más habitantes puedan acceder a un crédito hipotecario, además las tasas de interés se mantendrán en un nivel accesible.

La expectativa de precios por $\mathrm{m} 2$ es el encarecimiento del $12 \%$ al $13 \%$ en los próximos 2 años. A pesar del alza nuestro país sigue siendo muy atractivo para las inversiones en este sector porque nuestro valor por $\mathrm{m} 2$ es más económico al compararlo con el precio por m2 de países como Colombia, Chile, Brasil, Ecuador, entre otros.

Por otro lado el comportamiento del consumidor ha ido variando, se están adecuando a la ofertas de departamentos pequeños, según el ex ministro de Vivienda, Carlos Bruce, el consumidor es cada vez más independiente y está dispuesto a vivir en áreas pequeñas pero si tener áreas comunes. 


\subsection{Análisis de la competencia}

Para hacer este análisis se recorrió la zona y los alrededores del conjunto habitacional Villa de Atletas y se halló lo siguiente:

- No existe una oferta inmobiliaria de departamentos multifamiliares

- Venta de terrenos por parte de la empresa Menorca

- Venta y alquiler de departamentos que están desarrollados sobre una casa

- Alquiler de cuartos

- Proyectos de departamentos de máximo 5 pisos

La zona donde se ubica Villa de Atletas, cuenta con comercios a sus alrededores; restaurantes, locales automotrices, librerías y entidades educativas particulares y estatales. En la Av. El Sol se ubica la entrada principal del conjunto habitacional, esta avenida ha sido restaurada por motivo del evento de los Panamericanos, ambas pistas están renovadas y cuentan con una berma amplia al medio con áreas verdes, bancas y la iluminación adecuada.

La ubicación del conjunto habitacional es ideal porque cuenta con salidas cercanas a la Panamericana Sur y cerca de la Línea 1 del Metro de Lima, centro comercial Unicachi y al Parque Industrial.

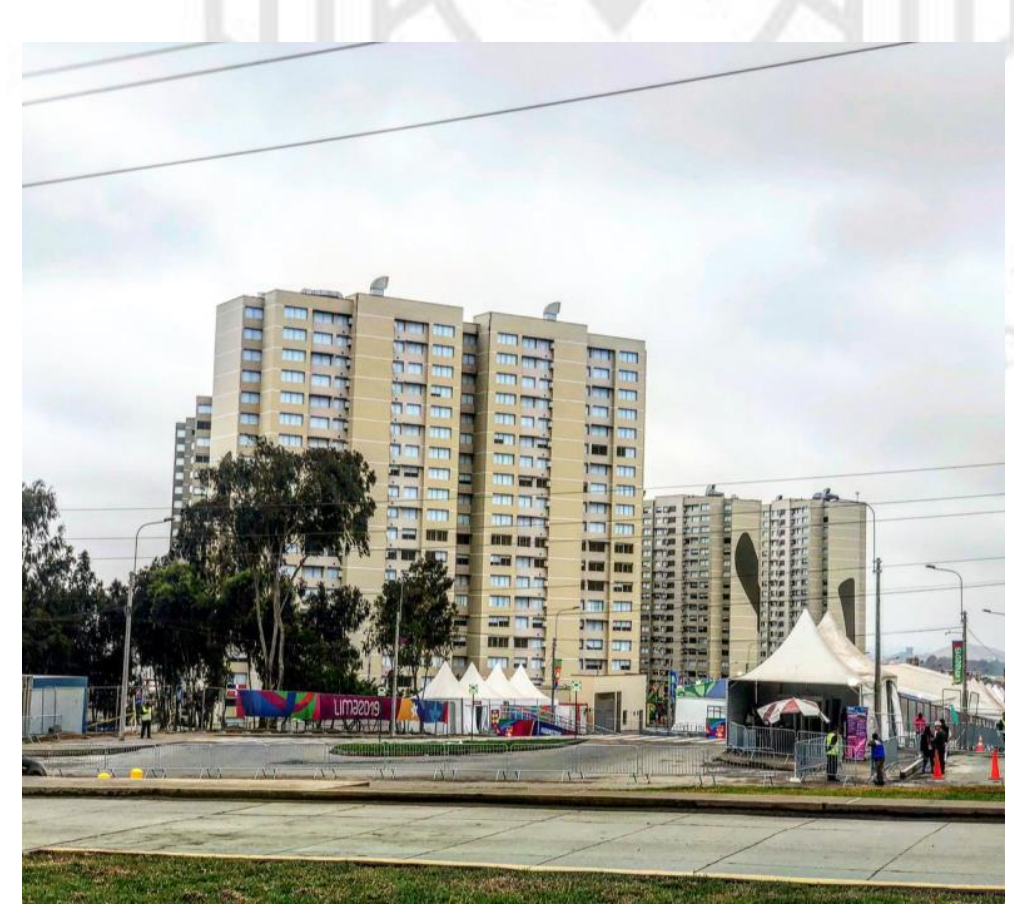

Figura 5: Exteriores del proyecto Villa de Atletas. Fuente: Elaboración propia. 


\subsubsection{Benchmark}

Para la una mejor toma de decisiones, hicimos una análisis de la competencia. Basándonos en los siguientes puntos:

- Precio por metro

- Distribución

- Crédito Fondo Mivivienda

- Áreas comunes

Ver aquí el cuadro comparativo: https://drive.google.com/open?id=15v7a6Q3R2CxkHFv8SFMQ_byHGkLYR3W

\subsubsection{Actual Inmobiliaria Chorrillos}

Actual inmobiliaria tiene una oferta de departamentos multifamiliares de tres torres en la zona de Chorrillos, la información que presenta en su web es completa, cuenta con información general y específica. Descripción del proyecto, equipamiento del multifamiliar, áreas comunes, la ubicación exacta con un mapa y todos los puntos de comercio y salidas de interés.

En la sección de "Plantas" cuenta con los planos de cada tipo de departamento, donde se puede apreciar la distribución y la medida total de cada uno de ellos por piso. Además se puede elegir el metraje que deseas ver o filtrar por el número de cuartos. En cada plano mostrado se aprecia el botón de cotizar que al presionar se despliega un formulario para datos. Al solicitar una cotización la respuesta tarda alrededor de un día. En la parte multimedia está colgado un brochure en línea, este es informativo pero prioriza lo visual, colocando fotos alusivas a su departamento piloto y sus áreas comunes. En esta pestaña también está colgado el video de la visita virtual del proyecto, este video te lleva a un canal de Youtube propio de la inmobiliaria.

El estado de la obra es de entrega inmediata, el precio por metro cuadrado es de 4,750 soles, no tiene información acerca de la cuota inicial ni con que bancos está trabajando el proyecto pero describe otros beneficios a los cuales se puede acceder como el Bono Azul, que se trata de un descuento de 15000 soles sobre el precio total. Este bono aplica para el proyecto de Chorrillos y Costanera. También cuentan con programas como "Bono de referidos" y "Complementamos tu cuota inicial". Las áreas comunes 
del proyecto los Sauces son; Sala de Juegos para niños, Gimnasio, Lavandería, Patio común, Sum y sala de adultos

\subsubsection{Enacorp "Valle Grande"}

Enacorp ofrece en Carabayllo la obra Valle Grande, un condominio club que cuenta con varios edificios de aproximadamente 5 pisos cada uno. La distribución es de 3 dormitorios, dos baños, sala comedor y cocina con lavandería. Los espacios comunes son; Gimnasio, piscina de niños, piscina de adultos, salón de reuniones, parque de bicicletas, juegos para niños, parque en el interior, bodegas y estacionamientos.

La información en la página web, no está completa puesto que no señala cuantos edificios serán en total, no hay información de los tipos de departamentos y su metraje, sólo colocan desde $54.82 \mathrm{~m} 2$. Al escribir por medio de su chat virtual, su respuesta es inmediata y después de haber dejado todos los datos requeridos te dan la información a la brevedad. Otro punto a tomar en cuenta es que tienen un recorrido virtual en 3D realista, que te ubica en tu futuro departamento desde la entrada.

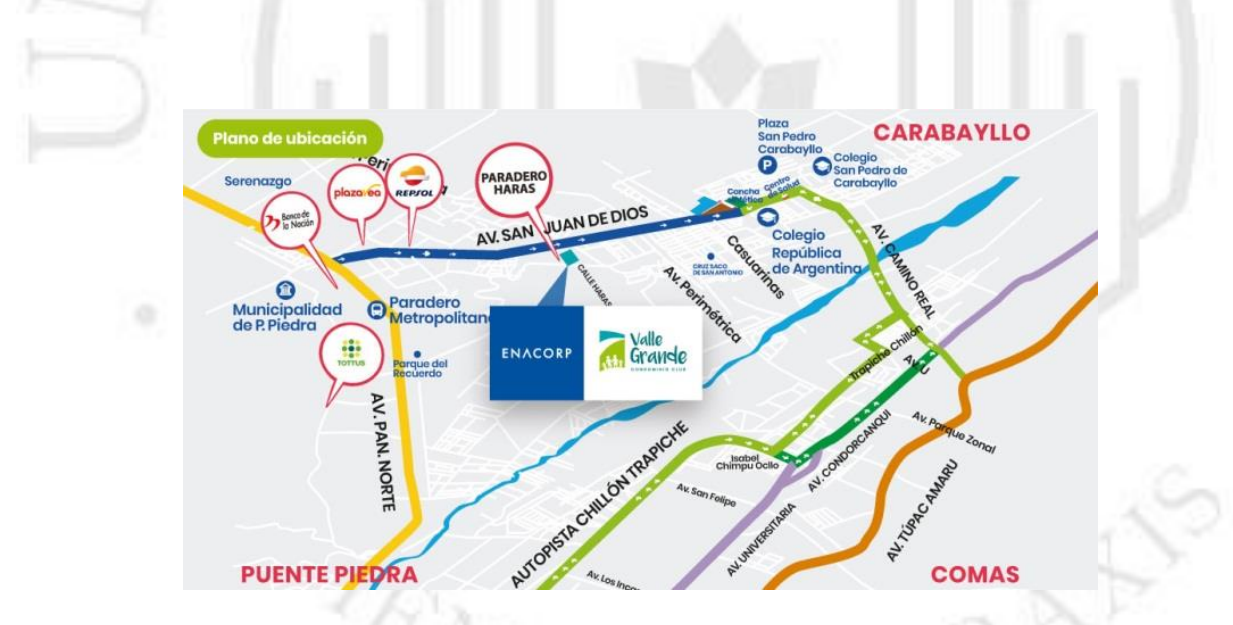

Figura 6: Plano de la ubicación del proyecto Enacorp. Fuente: Enacorp

En la página web actualizan las fotos reales de los avances del proyecto y al dejar los datos en el landing page, se comunican directamente vía Whatsapp mandando información, brochure, ubicación y horarios para concertar una cita.

\subsubsection{Competencia Indirecta}

Venta de departamentos a través de Urbania.pe, Adondevivir.com, OLX. Existen variedad de ofertas de venta de departamentos en Villa el Salvador a través de estas 
páginas, departamentos usados que pertenecen a multifamiliares, de antigüedad de 4 años en adelante. Las características de estos departamentos son de un metraje entre las $60 \mathrm{~m} 2$ hasta los $75 \mathrm{~m} 2$, con una distribución de 3 dormitorios, 1 baño, cocina, lavandería, sala comedor y en algunos casos cochera. En el caso de los multifamiliares cuenta con espacios comunes como área de juegos para niños y áreas verdes. Los precios oscilan entre los 55 mil dólares hasta los 77 mil dólares, dependiendo del metraje.

Existe también la oferta de proyectos de departamentos con 5 pisos como máximo, están ubicados cerca al conjunto habitacional Villa de Atletas, en la urbanización Villa Flores y sector 3. Los departamentos de estreno tienen un metraje de entre $90 \mathrm{~m} 2-100$ $\mathrm{m} 2$ con 3 cuartos, 2 baños, sala-comedor, estudio, lavandería y algunos cuentan con terraza. Su precio oscila entre los 60 mil a 80 mil dólares, un precio aproximado de 666.6 dólares el m2 hasta 800 dólares, algunos de estos departamentos son vendidos por intermediarios como REMAX.

En el caso de los departamentos usados cercanos a la zona, tienen un precio aproximado de 540 dólares el m 2 con una oferta de distribución similar. El alquiler de los departamentos oscila entre $500-800$ soles mensuales.

El resumen de nuestra investigación del tipo de ofertas de Viviendas de la zona esta presentada por porcentajes en el siguiente gráfico.

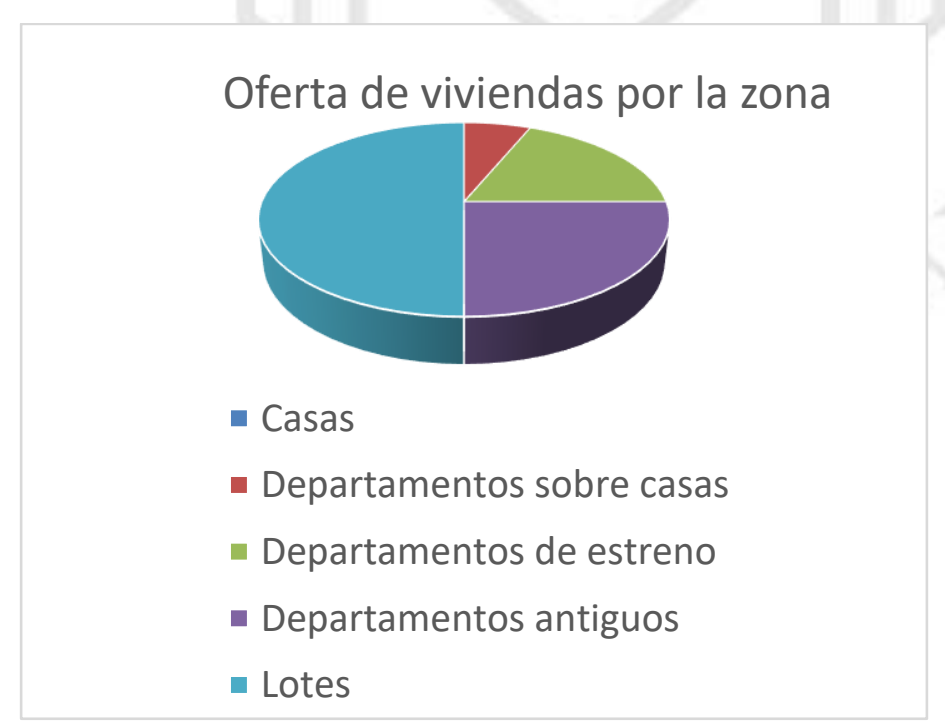

Figura 7: Oferta de venta de vivienda por la zona. Fuente: Elaboración propia 


\section{ANÁLISIS DEL PÚBLICO OBJETIVO}

\subsection{Análisis cuantitativo}

\subsubsection{Perfil demográfico}

Para hacer un análisis a profundidad sobre el público objetivo planteado "Jóvenes y adultos desde los 25 años de edad en adelante, de los NSE C y D. Todo aquel que tenga el anhelo de adquirir una vivienda propia", recurrimos a consultar data del estudio de Perfiles Socioeconómicos de Lima Metropolitana 2017 (IPSOS) y Estadística Poblacional Lima Metropolitana 2019 (IPSOS), donde iremos detallando algunos hallazgos claves identificados.

Encontramos mayor proporción de personas en el NSE C a comparación del NSE D, en todo Lima Metropolitana.

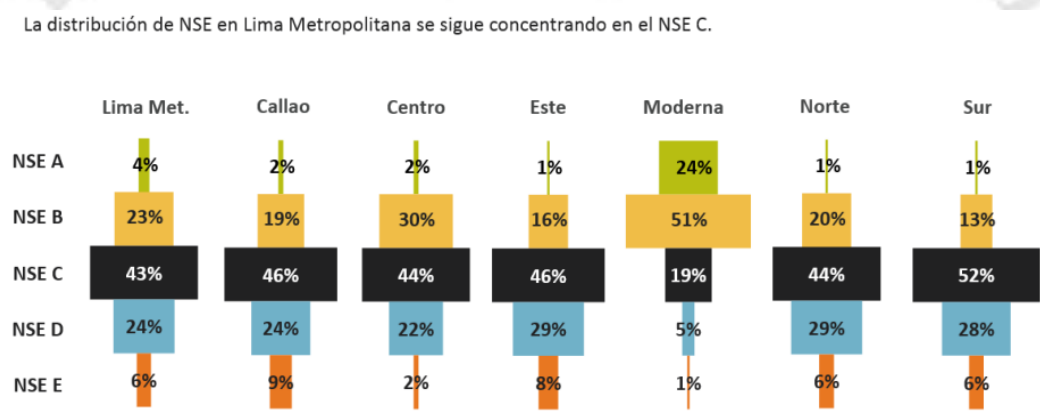

Figura 8: Distribución de NSE en Lima Metropolitana. Fuente: IPSOS.

Al comparar los ingresos económicos del NSE C y D, observamos que son ampliamente diferenciados. El NSE C tiene una ventaja significativa sobre el NSE D.

\begin{tabular}{|l|c|c|c|c|c|c|}
\multicolumn{7}{|c|}{ Por NSE (S/) } \\
\hline NSE & $\mathbf{2 0 0 5}$ & $\mathbf{2 0 1 0}$ & $\mathbf{2 0 1 4}$ & $\mathbf{2 0 1 5}$ & $\mathbf{2 0 1 6}$ \\
\hline NSE A & 8,435 & 11,168 & 11,596 & 10,860 & 14,205 \\
\hline NSE B & 3,848 & 4,721 & 5,869 & 5,606 & 7,297 \\
\hline NSE C & 2,387 & 3,104 & 3,585 & 3,446 & 4,193 \\
\hline NSE D & 1,545 & 1,957 & 2,227 & 2,321 & 2,851 \\
\hline NSE E & 1,048 & 1,303 & 1,650 & 1,584 & 2,120 \\
\hline
\end{tabular}

Figura 9: Ingresos económicos en los últimos años en Lima Metropolitana. Fuente: IPSOS. 


\subsubsection{Composición familiar}

Observamos que en el NSE C y en el NSE D los mayores porcentajes se concentran en el "Nuclear con hijos" y "Ampliado/Compuesto".

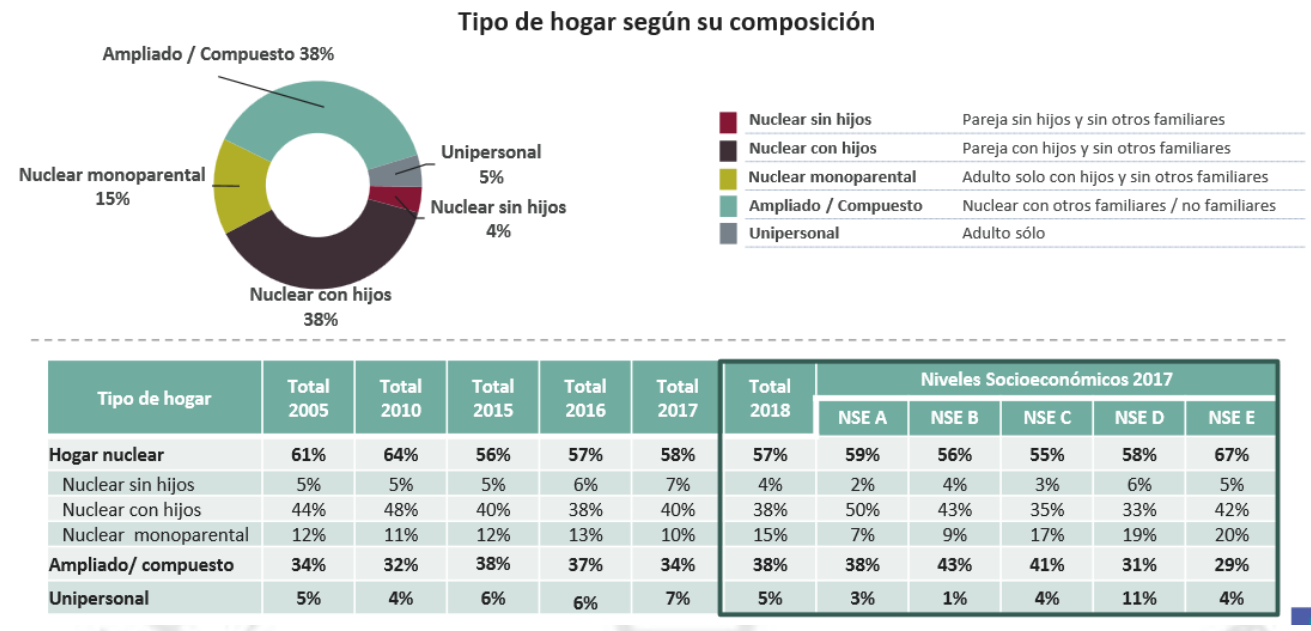

Figura 10: Tipo de hogar según su composición en Lima Metropolitana. Fuente: IPSOS.

También observamos que la mayor parte del NSE C y del NSE D tienen familias que están compuestas por 3 o más miembros.

Número de miembros que viven en el hogar

\begin{tabular}{|l|c|c|c|c|c|c|}
\hline Años & Uno & Dos & Tres & Cuatro & $\begin{array}{c}\text { Cinco } \\
\text { o más }\end{array}$ & Promedio \\
\hline $\mathbf{2 0 0 5}$ & $7 \%$ & $10 \%$ & $19 \%$ & $25 \%$ & $39 \%$ & 4.1 \\
\hline $\mathbf{2 0 1 0}$ & $10 \%$ & $12 \%$ & $19 \%$ & $24 \%$ & $34 \%$ & 3.9 \\
\hline $\mathbf{2 0 1 4}$ & $9 \%$ & $15 \%$ & $20 \%$ & $24 \%$ & $32 \%$ & 3.9 \\
\hline $\mathbf{2 0 1 5}$ & $10 \%$ & $17 \%$ & $21 \%$ & $23 \%$ & $29 \%$ & 3.7 \\
\hline $\mathbf{2 0 1 6}$ & $10 \%$ & $15 \%$ & $21 \%$ & $26 \%$ & $28 \%$ & 3.7 \\
\hline $\mathbf{2 0 1 7}$ & $10 \%$ & $15 \%$ & $21 \%$ & $24 \%$ & $29 \%$ & 3.8 \\
\hline \multicolumn{7}{|c|}{ Por NSE } \\
\hline
\end{tabular}

Figura 11: Número de miembros que viven en el hogar. Fuente: IPSOS. 


\subsubsection{Tenencia de propiedades, bienes o servicios}

Tanto en el NSE C como en el NSE D vemos que no cuentan con ninguna propiedad.

\begin{tabular}{|l|c|c|c|c|c|c|}
\hline \multicolumn{1}{|c|}{ Inmuebles } & $\begin{array}{c}\text { Total } \\
\text { 2017 }\end{array}$ & $\begin{array}{c}\text { NSE } \\
\text { A }\end{array}$ & $\begin{array}{c}\text { NSE } \\
\text { B }\end{array}$ & $\begin{array}{c}\text { NSE } \\
\text { C }\end{array}$ & $\begin{array}{c}\text { NSE } \\
\text { D }\end{array}$ & $\begin{array}{c}\text { NSE } \\
\text { E }\end{array}$ \\
\hline $\begin{array}{l}\text { Algún terreno agrícola / } \\
\text { fundo / chacra } \\
\begin{array}{l}\text { Alguna vivienda particular en } \\
\text { zona urbana (2da. vivienda) }\end{array}\end{array}$ & $2 \%$ & $9 \%$ & $4 \%$ & - & $1 \%$ & $2 \%$ \\
\hline $\begin{array}{l}\text { Algún terreno en zona } \\
\text { urbana }\end{array}$ & $1 \%$ & $4 \%$ & $3 \%$ & - & - & - \\
\hline $\begin{array}{l}\text { Alguna vivienda de playa o } \\
\text { campo }\end{array}$ & $1 \%$ & $6 \%$ & $1 \%$ & - & - & - \\
\hline $\begin{array}{l}\text { Algún establecimiento para } \\
\text { negocio }\end{array}$ & - & $2 \%$ & - & - & - & - \\
\hline $\begin{array}{l}\text { Ninguno / No tengo otras } \\
\text { propiedades }\end{array}$ & $93 \%$ & $64 \%$ & $86 \%$ & $97 \%$ & $98 \%$ & $96 \%$ \\
\hline
\end{tabular}

Figura 12: Tenencia de alguna propiedad. Fuente: IPSOS.

El NSE C y el NSE D no tienen un auto o camioneta particular, pero sí tienen bicicletas.

Figura 13: Tenencia de vehículo particular. Fuente: IPSOS.

Hay un mayor porcentaje del NSE D que no cuentan con TV cable, Teléfono e Internet.

Por NSE 2016

\begin{tabular}{|l|c|c|c|c|c|}
\hline \multicolumn{1}{|c|}{ Tenencia de... } & NSE A & NSE B & NSE C & NSE D & NSE E \\
\hline Celular & $97 \%$ & $97 \%$ & $93 \%$ & $90 \%$ & $88 \%$ \\
\hline TV cable & $93 \%$ & $84 \%$ & $66 \%$ & $36 \%$ & $14 \%$ \\
\hline Teléfono & $92 \%$ & $81 \%$ & $55 \%$ & $18 \%$ & $7 \%$ \\
\hline Internet & $96 \%$ & $85 \%$ & $54 \%$ & $15 \%$ & $7 \%$ \\
\hline
\end{tabular}

Figura 14: Tenencia de servicios. Fuente: IPSOS. 


\subsubsection{Características de su vivienda}

Vemos que en el NSE C viven en espacios de $90 \mathrm{~m} 2$, en cambio en el NSE D, en espacios de $120 \mathrm{~m} 2$.

\section{Por NSE 2018}

\begin{tabular}{|l|c|c|c|c|c|}
\hline & NSE A & NSE B & NSE C & NSE D & NSE E \\
\hline $550 \mathrm{~m} 2$ & $2 \%$ & $2 \%$ & $18 \%$ & $11 \%$ & $9 \%$ \\
\hline $51-100 \mathrm{~m} 2$ & $30 \%$ & $35 \%$ & $18 \%$ & $17 \%$ & $33 \%$ \\
\hline $101-150 \mathrm{~m} 2$ & $20 \%$ & $13 \%$ & $8 \%$ & $36 \%$ & $33 \%$ \\
\hline $150 \mathrm{~m} 2<$ & $43 \%$ & $23 \%$ & $21 \%$ & $12 \%$ & $4 \%$ \\
\hline MEDIANA (m2) & $\mathbf{1 3 9}$ & $\mathbf{1 1 0}$ & $\mathbf{9 0}$ & $\mathbf{1 2 0}$ & $\mathbf{1 0 0}$ \\
\hline
\end{tabular}

Figura 15: Características de sus viviendas. Fuente: IPSOS.

Tanto en el NSE C y en el NSE D, tienen viviendas de uno a tres ambientes, en los cuales dos son utilizados para dormir.

\section{Por NSE 2017}

\begin{tabular}{|l|c|c|c|c|c|}
\hline \# ambientes & NSE A & NSE B & NSE C & NSE D & NSE E \\
\hline Uno a tres & $10 \%$ & $27 \%$ & $46 \%$ & $68 \%$ & $89 \%$ \\
\hline Cuatro a seis & $75 \%$ & $61 \%$ & $49 \%$ & $30 \%$ & $10 \%$ \\
\hline Siete a nueve & $13 \%$ & $10 \%$ & $5 \%$ & $2 \%$ & $1 \%$ \\
\hline Diez a más & $2 \%$ & $2 \%$ & $0 \%$ & $0 \%$ & $0 \%$ \\
\hline PROMEDIO & $\mathbf{5 . 1}$ & $\mathbf{4 . 5}$ & $\mathbf{3 . 8}$ & $\mathbf{3 . 0}$ & $\mathbf{2 . 2}$ \\
\hline
\end{tabular}

Figura 16: Ambientes con las que cuentan su viviendas. Fuente: IPSOS.

\begin{tabular}{|l|c|c|c|c|c|}
\hline \multicolumn{7}{|c|}{ Por NSE 2017 } \\
\hline \# habitaciones & NSE A & NSE B & NSE C & NSE D & NSE E \\
\hline Ninguno & $0 \%$ & $0 \%$ & $2 \%$ & $10 \%$ & $21 \%$ \\
\hline Uno & $2 \%$ & $7 \%$ & $15 \%$ & $27 \%$ & $36 \%$ \\
\hline Dos & $23 \%$ & $28 \%$ & $37 \%$ & $36 \%$ & $31 \%$ \\
\hline Tres & $41 \%$ & $40 \%$ & $29 \%$ & $20 \%$ & $10 \%$ \\
\hline Cuatro a más & $34 \%$ & $24 \%$ & $16 \%$ & $6 \%$ & $2 \%$ \\
\hline PROMEDIO & $\mathbf{3 . 3}$ & $\mathbf{3 . 0}$ & $\mathbf{2 . 5}$ & $\mathbf{1 . 9}$ & $\mathbf{1 . 4}$ \\
\hline
\end{tabular}

Figura 17: Número de habitaciones en sus vivienda. Fuente: IPSOS. 
De igual manera, en ambos segmentos solamente tienen un baño.

\begin{tabular}{|l|c|c|c|c|c|}
\hline \multicolumn{7}{|c|}{ Por NSE 2017 } \\
\hline \multicolumn{1}{|c|}{ \# de baños } & NSE A & NSE B & NSE C & NSE D & NSE E \\
\hline Uno & $5 \%$ & $45 \%$ & $66 \%$ & $86 \%$ & $51 \%$ \\
\hline Dos & $31 \%$ & $39 \%$ & $26 \%$ & $9 \%$ & $2 \%$ \\
\hline Tres o más & $64 \%$ & $16 \%$ & $8 \%$ & $1 \%$ & $0 \%$ \\
\hline No tiene baño & $0 \%$ & $0 \%$ & $0 \%$ & $4 \%$ & $47 \%$ \\
\hline PROMEDIO GENERAL & $\mathbf{3 . 4}$ & $\mathbf{1 . 8}$ & $\mathbf{1 . 4}$ & $\mathbf{1 . 1}$ & $\mathbf{0 . 6}$ \\
\hline
\end{tabular}

Figura 18: Tenencia de baño en sus vivienda. Fuente: IPSOS.

Encontramos que solamente una minoría del NSE C y NSE D cuentan con jardín externo, terraza o cochera.

Por NSE 2018

\begin{tabular}{|l|c|c|c|c|c|}
\hline \multicolumn{1}{|c|}{ Tenencia de... } & NSE A & NSE B & NSE C & NSE D & NSE E \\
\hline Jardín externo & $64 \%$ & $52 \%$ & $21 \%$ & $18 \%$ & $11 \%$ \\
\hline Cochera / garaje & $78 \%$ & $24 \%$ & $9 \%$ & $9 \%$ & $2 \%$ \\
\hline Terraza & $64 \%$ & $25 \%$ & $10 \%$ & $1 \%$ & - \\
\hline Jardín interno & $40 \%$ & $17 \%$ & $8 \%$ & $6 \%$ & $3 \%$ \\
\hline Zona de parrilla & $54 \%$ & $15 \%$ & $2 \%$ & $1 \%$ & - \\
\hline Piscina construida & $12 \%$ & - & - & - & - \\
\hline
\end{tabular}

Figura 19: Tenencia de exteriores en sus vivienda. Fuente: IPSOS.

\subsubsection{Sobre su perfil laboral}

Si analizamos la labor que cumple cada miembro del hogar. Encontramos que el Jefe de Hogar del NSE C son en mayor proporción empleados, independientes y obreros, en el NSE D son obreros e independientes.

\begin{tabular}{|l|c|c|c|c|c|}
\hline \multicolumn{2}{|c|}{ Por NSE 2016 } \\
\hline \multicolumn{1}{|c|}{ Ocupación del jefe del hogar } & NSE A & NSE B & NSE C & NSE D & NSE E \\
\hline Trabajador independiente & $8 \%$ & $18 \%$ & $37 \%$ & $42 \%$ & $43 \%$ \\
\hline Empleador o patrono & $8 \%$ & $10 \%$ & $9 \%$ & $7 \%$ & $4 \%$ \\
\hline Empleado & $82 \%$ & $62 \%$ & $27 \%$ & $13 \%$ & $10 \%$ \\
\hline Obrero & $1 \%$ & $9 \%$ & $23 \%$ & $32 \%$ & $38 \%$ \\
\hline Trabajador del hogar & $0 \%$ & $1 \%$ & $3 \%$ & $4 \%$ & $5 \%$ \\
\hline Trabajador familiar no remunerado & $0 \%$ & $1 \%$ & $2 \%$ & $1 \%$ & $1 \%$ \\
\hline
\end{tabular}

Figura 20: Ocupación del Jefe de Hogar. Fuente: IPSOS.

Por otro lado, observamos que la mayor parte de las parejas del jefe del hogar en los NSE C y D trabajan pero no es un empleo fijo. 


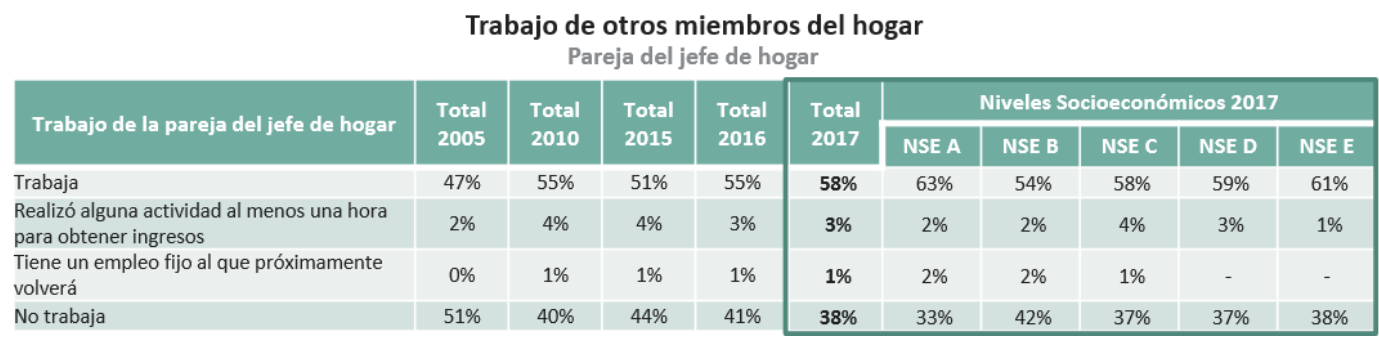

Figura 21: Trabajo de otros miembros del hogar. Fuente: IPSOS.

\subsubsection{Ingresos económicos}

Según lo visto, observamos que el promedio de ingreso de hogar en el NSE C es de S/. 3,100 y en el NSE D S/ 2,208.

Comparativo 2005-2016

\begin{tabular}{|c|c|c|c|c|c|}
\hline NSE & 2005 & 2010 & 2015 & 2016 & 2017 \\
\hline NSE A & $S / 5,783$ & $S / 6,998$ & $S / 7,362$ & $S / 7,800$ & $S / 7,908$ \\
\hline NSE B & $S / 3,433$ & $S / 3,819$ & $S / 4,249$ & $S / 4,815$ & $S / 4,807$ \\
\hline NSE C & $S / 2,021$ & $S / 2,558$ & $S / 2,840$ & $S / 3,122$ & $S / 3,100$ \\
\hline NSE D & $S / 1,376$ & $S / 1,734$ & $S / 2,034$ & $S / 2,211$ & $S / 2,208$ \\
\hline NSE E & $S / 1,031$ & $S / 1,301$ & $S / 1,479$ & $S / 1,719$ & $S / 1,627$ \\
& & & &
\end{tabular}

Figura 22: Ingreso mensual según NSE. Fuente: IPSOS.

Así mismo, si observamos el excedente de dinero con el que cuentan, después de sus gastos, vemos que en el NSE C tiene más disponibilidad de gasto que en el NSE D.

Rubros de gastos

\begin{tabular}{|c|c|c|c|c|c|c|}
\hline \multirow[b]{2}{*}{ Rubros } & \multirow{2}{*}{$\begin{array}{c}\text { Total } \\
2017 \\
\text { (s/) }\end{array}$} & \multicolumn{5}{|c|}{ Niveles Socioeconómicos 2017 (S/) } \\
\hline & & NSE A & NSE B & NSE C & NSE D & NSE E \\
\hline Alimentos y bebidas & 1,309 & 1,666 & 1,512 & 1,312 & 1,144 & 914 \\
\hline Alquiler de vivienda, combustible, electricidad y conservación de la vivienda & 841 & 2,098 & 1,333 & 751 & 430 & 270 \\
\hline Esparcimiento, diversión, cultura y enseñanza & 332 & 1,081 & 555 & 268 & 148 & 89 \\
\hline Cuidado, conservación de la salud y servicios médicos & 277 & 767 & 401 & 245 & 159 & 118 \\
\hline Transporte y comunicaciones & 241 & 921 & 421 & 181 & 90 & 46 \\
\hline Vestido y calzado & 121 & 256 & 169 & 109 & 80 & 69 \\
\hline Muebles, enseres y mantenimiento de vivienda & 115 & 596 & 162 & 80 & 56 & 42 \\
\hline Equipamiento del hogar & 44 & 190 & 74 & 31 & 16 & 8 \\
\hline Otros bienes y servicios & 133 & 334 & 180 & 122 & 85 & 71 \\
\hline Disponible para otros rubros & 1,332 & 5,197 & 2,297 & 959 & 551 & 360 \\
\hline
\end{tabular}

Figura 23: Gastos por NSE. Fuente: IPSOS. 


\subsubsection{Sobre su ciclo de vida}

Por otro lado, observamos que hay una proporción mínima de parejas jóvenes en ambos segmentos. La proporción de hogares con hijos menores de 18 años es más en el NSE D frente al NSE C. Y que el porcentaje de "hogares con hijos mayores de 18 años" o "fuera de ciclo" es mayor en el NSE D frente al NSE C.

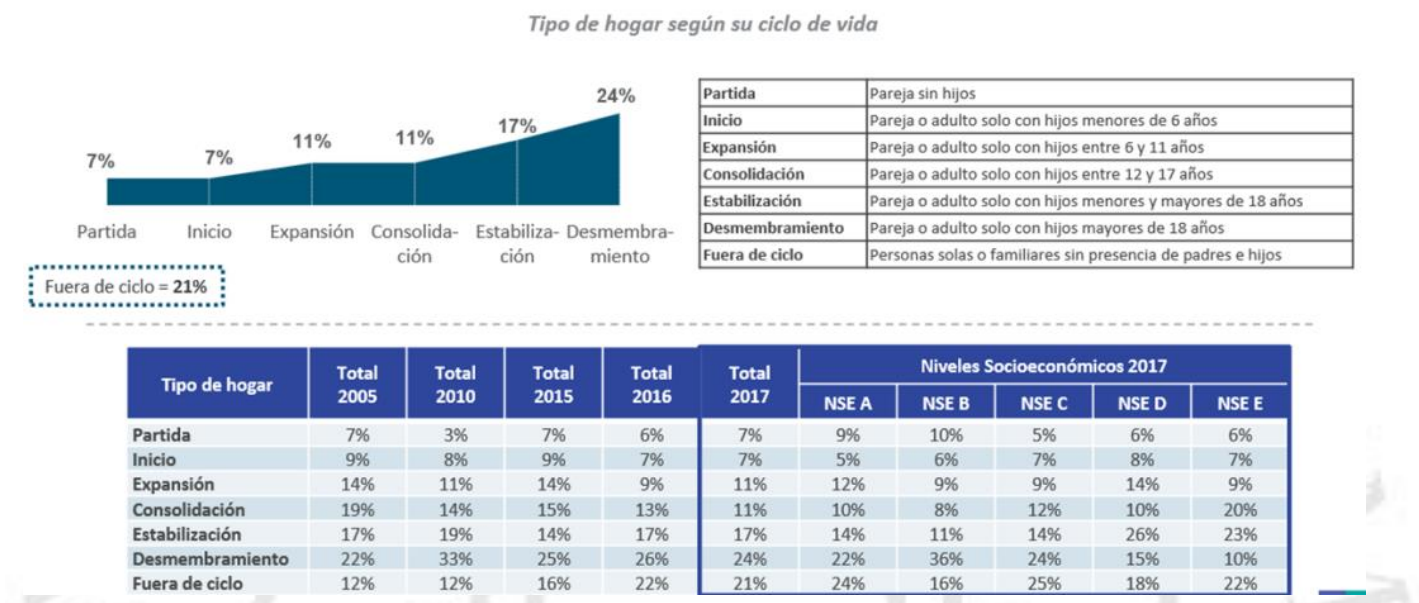

Figura 24: Tipo de hogar según su ciclo de vida. Fuente: IPSOS.

\subsubsection{Sobre su consumo de medios}

Observamos que el consumo de medios digitales del NSE C (46\%) se encuentra a un nivel similar comparándolo con su consumo de los medios tradicionales (54\%). Por otro lado el consumo del NSE D aún tiene mayor relevancia en los medios tradicionales.

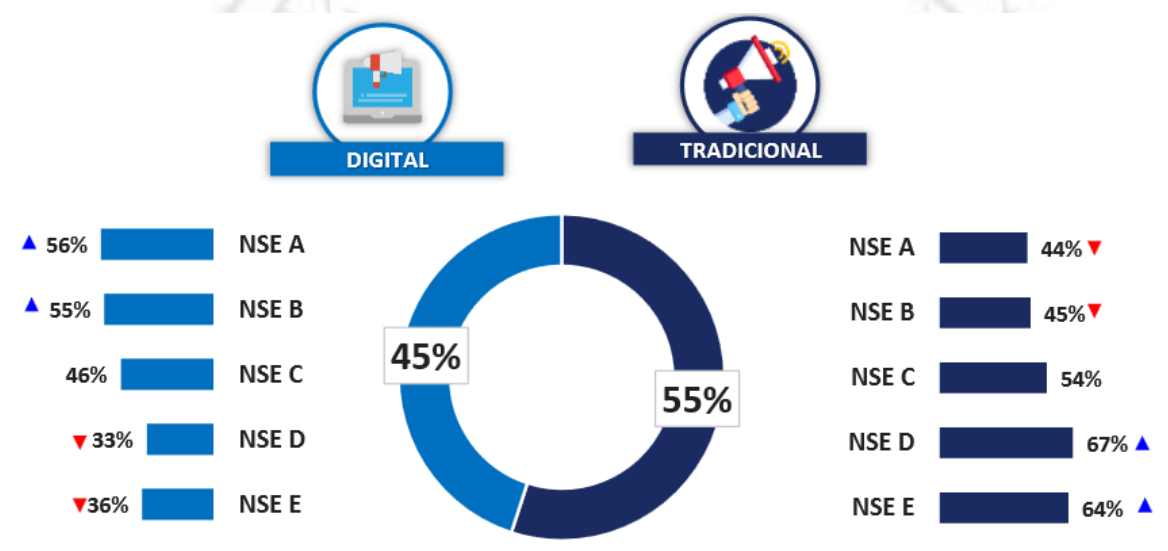

Figura 25: Share de consumo de medios. Fuente: IPSOS 


\subsubsection{Tiempo del uso de medios}

En cuanto a los medios tradicionales, observamos que en el NSE C y D, la televisión y la radio tienen mayor presencia con un promedio de uso de 10 y 7 horas respectivamente.

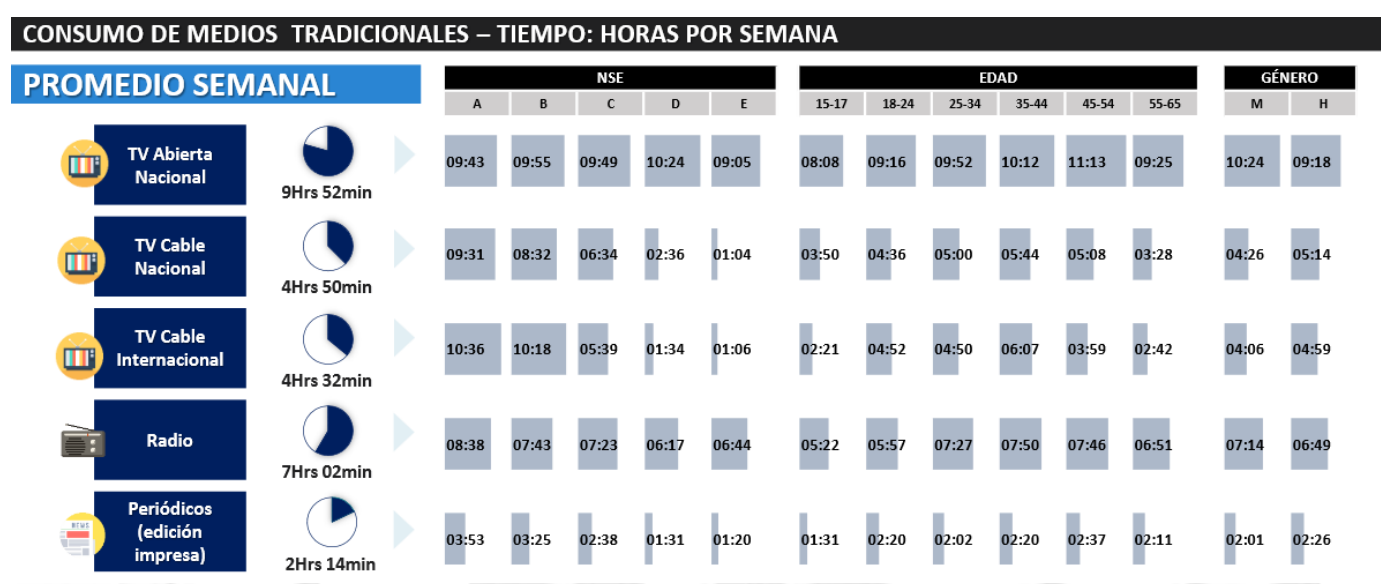

Figura 26: Consumo de medios tradicionales - Horas por semana. Fuente: IPSOS

En cuanto a los medios digitales, observamos que en el NSE C, Youtube, Facebook y Netflix tienen mayor tempo de uso y en el NSE D solo Youtube y Facebook. En cuanto a las personas de 25 a 40 años predomina el consumo en Facebook y Youtube y Netflix estarían en un segundo lugar.

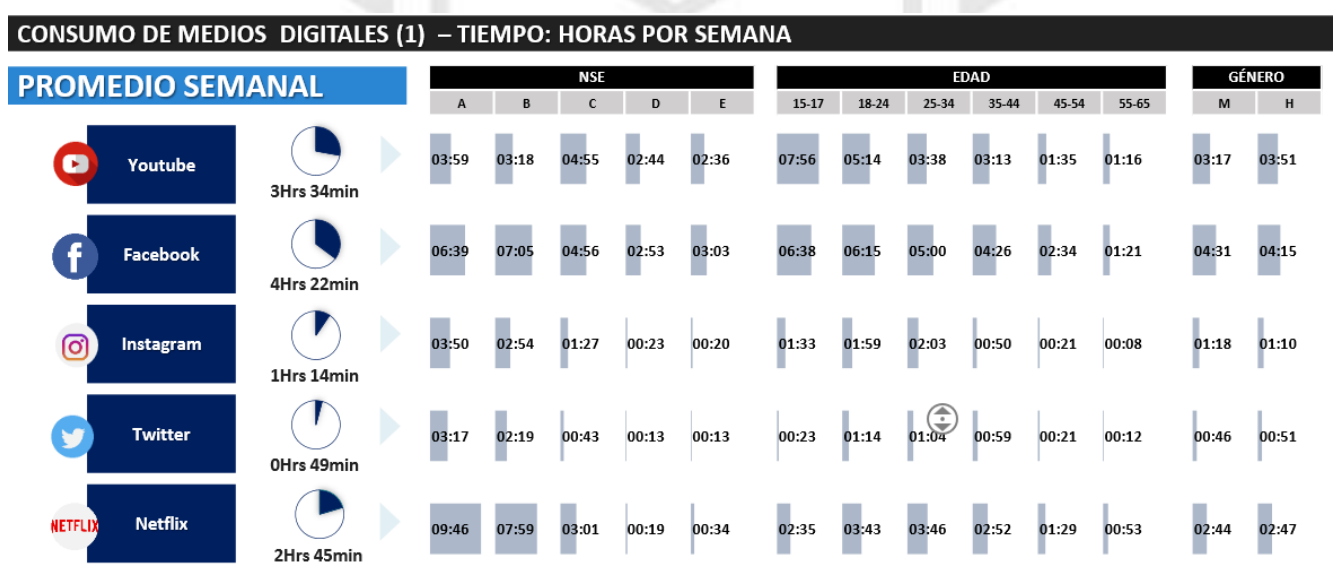

Figura 27: Consumo de medios tradicionales - Horas por semana. Fuente: IPSOS 
Por lo tanto, creemos que:

- Debemos dirigirnos al NSE C porque en ellos encontramos mayor proporción de hogares con mayores ingresos y mayor capacidad de deuda.

- Debemos dirigirnos al NSE C ya que a diferencia del NSE D, encontramos la mayor proporción de personas empleadas que tendrían mayor facilidad para acceder a créditos hipotecarios.

- Debemos dirigirnos a personas de 25 a 40 años, ya que ellos se encuentran en el rango de familias que tienen hijos menores de 18 años.

\subsection{Entrevistas a profundidad}

Con el fin de conocer mejor a nuestro público objetivo, se hicieron 6 entrevistas a personas del target (NSE C de 25 a 40 años) para lograr entender sus alegrías, dolores y percepciones del proyecto.

\subsubsection{Motivaciones de compra (alegrías)}

- La compra de una vivienda significaría el logro de una meta soñada, probablemente la más importante a lo largo de su vida. Es una realización personal que les hace sentir que están cumpliendo con su familia.

- La compra de una vivienda significaría tener privacidad y comodidad dentro de su hogar, para poder hacer lo que consideren conveniente.

- Tener una vivienda propia significa tener independencia familiar. Es decir, dejar de estar bajo las reglas impuestas por la familia extendida y empezar a dirigir su propio hogar.

- Significa tener una inversión a futuro, sobre todo es considerado una herencia para sus hijos, dejarles algo para la vida. 


\subsubsection{Dolores}

- Los que viven en alquilado no se sienten satisfechos de pagar algo que no signifique una inversión, además que frecuentemente tienen discusiones con el dueño porque quieren hacer mejoras o cambios al inmueble.

- Los que viven en casa de familiares se sienten incómodos porque deben compartir espacios de la casa como la sala, cocina, incluso baños con suegros o cuñados. Además sienten que se involucran en problemas conyugales y hasta en la crianza de los hijos. También les disgusta el conflicto de intereses entre hermanos por el uso de la propiedad o tenencia final de la casa.

- Se sienten frustrados porque quisieran adquirir un vivienda para la familia que están formando, pero al ser independientes sienten que no pueden acceder a un crédito hipotecario. Además piensan que las cuotas mensuales podrían ser inaccesibles.

\subsubsection{Atributos valorados en una futura vivienda}

- Precio: buscan precios accesibles. Que les permita acceder a préstamos financieros.

- Cuotas accesibles: buscan que las cuotas sean accesibles, que les permita pagar la mensualidad sin ajustarse (seguir pagando los gastos básicos).

- Tamaño: buscan espacios amplios, ya que están acostumbrados a vivir en casas. Declaran vivir en casas de $120 \mathrm{~m} 2$ y $150 \mathrm{~m} 2$.

- Confianza /respaldo: debido a que en las noticias se escuchan diversos casos de estafa y mala calidad en la construcción, buscan una entidad que no haya tenido problemas financieros o denuncias.

- Seguridad: buscan que sea una zona iluminada, zona sin delincuencia, con seguridad alrededor (si es posible cerca a puestos policiales). 
- Ubicación: lugares cercanos a casas de su familia, cerca de centros comerciales, colegios y de fácil acceso a transporte público. Algunos buscan no alejarse tanto de su vivienda actual porque tienen lazos familiares y están acostumbrados costo de vida.

\subsubsection{Percepción del proyecto Villa de Atletas}

- Inicialmente cuando se habla sobre el condominio Villa de Atletas, son pocos los que lo reconocen con ese nombre; sin embargo, luego de asistirlos con el vínculo que tienen con los Juegos Panamericanos, lo reconocen inmediatamente.

- $\quad$ Perciben que se trata de un proyecto moderno porque fue creado este año para atletas de todo el mundo, como consecuencia, se utilizó tecnología y calidad en la construcción.

- Perciben que se trata de un proyecto que tiene instalaciones deportivas importantes que permitiría que sus hijos puedan practicar alguno de estos deportes de manera segura (dentro el condominio).

- Una minoría, destaca las instalaciones para discapacitados. Si bien no tienen algún familiar con estas limitaciones, consideran que es un aporte importante a la sociedad.

- Los que viven cerca de la zona, les agrada las mejoras en los alredrores en cuanto a la seguridad e infraestructura.

\subsubsection{Conocimiento acerca de Fondo Mivivienda}

- En general la mayoría desconoce sobre este programa de financiamiento. Solo algunos tuvieron referencias por terceros pero no conocen exactamente de qué trata.

- $\quad$ Lo poco que saben es que es un programa que pide muchos requisitos. Tienen el temor que pidan documentos que no puedan sustentar como por ejemplo 
boletas de pago (al ser independientes, muchos informales consideran este es un requisito difícil de conseguir).

- Después de presentar el concepto, los aspectos más valorados son: Bono de Buen Pagador, cuotas fijas y Bono Verde. Sin embargo sigue el temor a no poder acceder a los requisitos que solicitan.

\section{DiÁGNOSTICO}

\subsection{Análisis FODA}

\subsubsection{Fortalezas}

- Está posicionado como un producto de buena calidad, ya que es conocido por ser una construcción especial para atletas internacionales de los Juegos Panamericanos y Parapanamericanos Lima 2019, por ello piensan que se utilizaron estándares de construcción buenos y modernos.

- El precio de adquisición es muy competitivo frente a los de la competencia que ofrecen lo mismo pero con precios más elevados.

- Los descuentos y facilidades para acceder a un crédito gracias a Fondo Mivivienda y Bono Verde.

- El producto se encuentra respaldado por la constructora Besco que tiene larga trayectoria en su rubro y con amplia experiencia en multifamiliares. El nivel de desconfianza de la entrega de los departamentos o la correcta funcionalidad de estos, disminuye.

- El proyecto cuenta con espacios de esparcimiento ya construidos (instalaciones deportivas) que suele ser atractivo para las familias porque consideran que sus hijos les sacaran provecho.

- Los alrededores del proyecto también fueron mejorados, debido al evento de los Juegos Panamericanos y Parapanamericanos 2019, lo que convierte a la zona más segura y de mejor ornato, lo que la hace un lugar más atractivo para vivir. 


\subsubsection{Oportunidades}

- Posibilidad de apalancarse de algunos factores publicitarios de los Juegos Panamericanos y Parapanamericanos Lima 2019, ya que han dejado buena impresión en todos los peruanos.

- Posibilidad de posicionarse como uno de los proyectos más ecosostenibles y de apoyo al medio ambiente, ya que sería de los pocos que cuenta con Bono Verde grado 2, la mayoría solo tiene el grado1.

- Aprovechar el Fondo de Arrendamiento para que las personas tengan más posibilidades para acceder a la compra de estos departamentos.

\subsubsection{Debilidades}

- Se percibe que el precio de mantenimiento será costoso, ya que son edificios altos, con ascensores y zonas de esparcimiento (instalaciones deportivas).

- El NSE al que queremos llegar está acostumbrados a vivir en casas y no en departamentos que implica aprender a vivir con otras familias ajenas y ponerse de acuerdo para cumplir una serie de normas.

- Encontramos que la mayoría de las personas no tienen conocimiento sobre los beneficios y el funcionamiento del Fondo Mivivienda ni del Bono Mivivienda Verde.

\subsubsection{Amenazas}

- Muchos han escuchado que varias personas tuvieron malas experiencias con la compra de sus departamentos o multifamiliares como: estafas con el dinero o mala calidad de los materiales (se terminan dañando rápidamente).

- Dentro de la oferta se puede encontrar lotes que conlleva a un gasto mayor posteriormente (por la construcción) pero garantiza la posibilidad de vivir en una casa y hasta utilizarlo como negocio. 
- En general, las personas tienen proyecciones de crecimiento que los lleva a un deseo de mejorar sus condiciones de vida, en ese sentido muchos quisieran cambiarse a un distrito que garantice más seguridad.

\subsection{Segmentación}

Se definió como público objetivo al nivel socioeconómico C por ser los de mayor poder adquisitivo (posibilidad de acceder a un crédito hipotecario) y por tener mayor porcentaje poblacional en Lima Metropolitana.

También definimos como público objetivo aquellos que están entre el rango de edad de 25 a 40 años porque según estudios es la edad donde empiezan una nueva etapa de su vida. Son aquellos que empiezan a formar una familia, por consecuencia buscan vivir en espacios privados donde los padres no puedan intervenir.

\subsection{Buyer persona}

Para tener mayor referencia de nuestro público objetivo, creemos importante armar un buyer persona que nos acompañará a lo largo de la implementación de la estrategia para no perder el foco.

\section{Alejandro Gómez:}

Edad: 30 años

Educación: técnico en electricidad

Ocupación: tiene un puesto donde repara artefactos

Familia: conviviente con hijo de 3 años

Vivienda: vive en casa de sus suegros

Alejandro tiene 30 años y vive en Villa el Salvador junto a su pareja y a su hijo de 3 años, en la casa de sus suegros. Él trabaja de manera independiente en un puesto de mercado, reparando artefactos eléctricos. Uno de sus mayores sueños es poder comprar una vivienda propia, ya que no le gusta vivir con sus suegros porque no tiene privacidad e 
intervienen en la educación de sus hijos; sin embargo, esta meta la ve lejana porque no cuenta con los ingresos suficientes.

Como la mayoría de los peruanos, al ver los Panamericanos, se sintió satisfecho y orgulloso del Perú por la organización del evento. Escuchó que los departamentos construidos para los deportistas ganadores los iban a vender, así que está atento a que se pongan a la venta, piensa que esos puedes ser más económicos y de buena calidad porque fueron construidos por el gobierno para deportistas internacionales. 


\subsection{Emphaty Map}

De igual manera, para entender mejor el entorno de nuestro público objetivo, vimos necesario elaborar un empathy map

\section{Alejandro Gómez}

\section{¿Qué piensa y siente?}

- Piensa que quieré ofrecērle mejor calidad de vida a sus hijos.

- Se siente frustrado porque ya no quiere vivir en casa de familiares, no se siente cómodo

- Piensa que quiere dejarle herencia a sus hijos.

- Piensan que la compra de un departamento es lejano y hasta imposible por los precios altos e inicial que piden.

¿Qué oye?

- Siente que la compra de un departamento es la meta de toda su vida, pero cada vez más lejana.

\section{¿Qué ve?}

- Oye que hay muchas estafas y malas experiencias cuando compran un departamento.

- Oye que la inicial y las cuotas para pagar una vivienda, son muy altas

- Oye que los departamentos de los Panamericanos se van a vender y darán facilidades de pago.

- Oye que los departamentos de los Panamericanos fueron construidos con mucha calidad por tratarse de un evento internacional

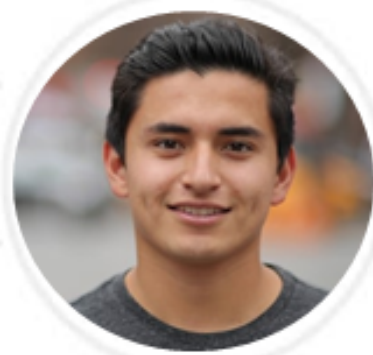

¿Qué dice y hace?

- Trata de ahorrar todos ius meses

- Visita proyectos pero ninguno se ajusta a sus necesidades.

- Fue a bancos para saber si podía obtener un crédito hipotecario pero la inicial era muy alta.

- Dice a su familia que hará lo posible para dejarles una vivienda como herencia.

\section{Miedos}

- No estar haciendo el buen papel de padre por no poder adquirir una vivienda propia.

- Endeudarse con un crédito muy alto y no poder pagarlo después.

- Ser estafado con alguna constructora o inmobiliaria (con respecto a la entrega o calidad del producto entregado)
- Que hay muchos proyectos de viviendas pero todos son inalcanzables por los precios elevados

- Que la Villa Panamericanos es una infraestructura grande que cuenta con espacios deportivos.

- Que la zona que rodea el proyecto ha mejorado: las pistas y la iluminación están mejor, perciben más seguridad.

\section{Objetivos /Metas}

- Ahorrar para pagar la inicial de crédito hipotecario.

- Comprar una vivienda propia antes que sus hijos crezcan (para que puedan vivir su niñez en esta). 


\section{OBJETIVOS}

\subsection{Objetivos de Marketing}

- Lograr que Villa de Atletas sea la primera alternativa de vivienda en las personas de 25-40 del NSE C, en los próximos 6 meses.

\subsection{Objetivos de Comunicación}

- Generar reconocimiento de la marca por lo menos en el $50 \%$ de nuestro público objetivo y motivarlo a la compra.

- Dar a conocer nuestra propuesta de valor y beneficios del producto al público objetivo.

- Generar una base de datos de los clientes potenciales.

- Incentivar la compra del producto

- Dar a conocer posibilidades de financiamiento a través del Fondo Mivivienda.

\section{IDENTIDAD DE MARCA}

\subsection{Nombre}

Como bien sabemos el nombre actual del proyecto es "Villa de Atletas"; sin embargo, creemos importante replantear el nombre y aprovechar el vínculo que tiene con los Juegos Panamericanos. De esta manera nos apalancamos del posicionamiento y reconocimiento que ya tiene la marca.

En nuestras entrevistas nos percatamos que ninguna de las personas a las que entrevistamos asociaba el lugar bajo el nombre de "Villa de Atletas" pero al mencionar que era sede de los Panamericanos, sí lo reconocía.

Por otro lado al hacer la investigación de la competencia pudimos darnos cuenta que para la venta de terrenos, departamentos y alquileres cercanos, en sus publicaciones hacen mención a la zona, bajo el nombre de "Villa Panamericanos" y figura con ese nombre al buscarlo en Google Maps.

También decidimos mantener el término "Villa", ya que hace referencia a una población, a la convivencia, a un lugar campestre, con áreas verdes. Como consecuencia, el público objetivo lo relaciona con un lugar relajante, amigable y de confianza. Además el lugar se encuentra en Villa el Salvador, mantener la palabra Villa para identificar su procedencia. Por ello hemos decidido el nombre "Villa Panamericanos". 


\subsection{Posicionamiento}

"Villa Panamericanos" es un espacio de viviendas construidas bajo estándares de calidad internacional con áreas sociales y deportivas que fomentan una vida saludable, aportando también con el cuidado del medio ambiente.

\subsection{Ventaja diferencial}

- Áreas deportivas: Villa Panamericanos alberga canchas multideportivas, pista de ciclismo y pista de jogging. Estos espacios son valorados por nuestro público objetivo ya que no cuentan con ofertas similares. Les gustaría que sus hijos estén influenciados por el deporte y que mejor que vivir en un multifamiliar equipado.

- Modernidad: Villa Panamericanos está construido con estándares internacionales de calidad, cuentan con marcas reconocidas en sus instalaciones y sus espacios son pensados en personas adultas o con discapacidad.

- Ecoamigable: Villa Panamericanos cuenta con mecanismos de última generación para el ahorro de energía y consumos en general.

\subsection{Reason why}

La razones para que nuestro público crea y compruebe nuestra oferta de valor son las siguientes:

Áreas deportivas: El proyecto fue hecho para el evento de Los Juegos Panamericanos y por esta razón era primordial que cuenten con áreas multideportivas para que ellos puedan entrenar las diferentes disciplinas en las que se desenvolvieron.

Modernidad: Por razón de ser un proyecto de envergadura internacional, se han utilizado productos de primera calidad en su construcción y se ha hecho un estudio para realizar recorridos adecuados para las personas con discapacidad.

Los deportistas que se han hospedado en Villa Panamericanos han quedado muy satisfechos y la prensa internacional nos ha tomado de ejemplo a seguir para los próximos Panamericanos en Chile.

Ecoamigable: La tecnología usada pra el ahorro de energía es muy novedosa, acreedora de un grado 2 en Bono Mivivienda Verde por cumplir con todos los requerimientos tales como 
ahorro de servicios, agua y energía, planta propia de tratamiento de aguas residuales y capacitación para lo usuarios.

\subsection{Personalidad de la marca}

- Mujer

- Segura

- Activa

- Familiar

La mujer es un miembro unificador en la familia por naturaleza, tiene sensibilidad y especial preocupación por los que integran su hogar. Villa Panamericanos es una mujer madre de familia administradora del hogar, la que acoge y direcciona a sus hijos, ella es activa porque cumple con los diferentes roles de madre y trabajadora. La seguridad que tiene en sí misma es la fuerza que la impulsa a alcanzar sus objetivos y los de su familia.

\subsection{Visión}

Ser un multifamiliar líder con espacios innovadores para disfrutar y que optimicen la calidad de vida de nuestros clientes y del planeta.

\subsection{Misión}

Brindar a nuestros clientes un producto inmobiliario bajo los mejores estándares de calidad e innovación, siendo responsables en nuestros tiempos de entrega y cumpliendo con honestidad todo lo ofrecido.

\subsection{Valores}

- Calidad: materiales adecuados para la construcción.

- Innovación: tecnología novedosa en ahorro de consumos.

- Compromiso: cumplir con los plazos de entrega y con lo ofrecido en el contrato.

\section{IDENTIDAD VISUAL}


6.1. Logo

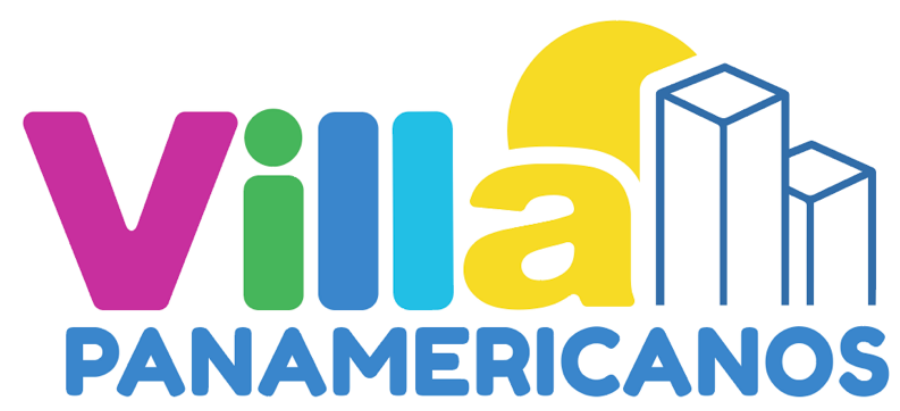

Ilustración 1: Logo Villa Panamericanos

\subsection{Manual de Logo}

Isotipo: está conformado por un par de edificios que grafican parte de las torres y el sol, elemento que representa el empezar de una nueva etapa de la vida, además refuerza el concepto de la convivencia con la naturaleza.

Tipografía: La tipografía usada en "Villa" es Arial Black, una letra a la que estamos muy familiarizados pero redondeada con bordes blancos, cada letra de distinto color. Este tipo de letra es categorizada como San Serif, una letra utilizada mucho para comercializar, letras limpias de fácil lectura que transmiten modernidad, seguridad y alegría.

La tipografía utilizada en la palabra "Panamericanos" es Freedoka One Regular, usada en mayúsculas. Este tipo de letra esta categorizada como San Serif, letra ideal para textos cortos.

\section{Colores:}

\section{Paleta de colores}
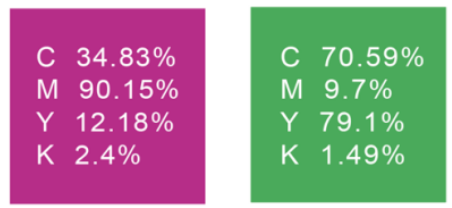

C $96.43 \%$

M $26.46 \%$

Y $8.15 \%$

K $1.05 \%$
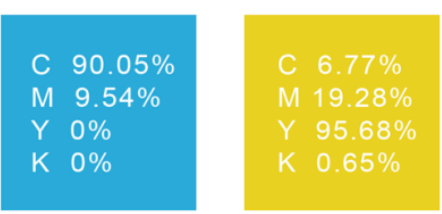

C $0 \%$

M $0 \%$

Y $0 \%$

K $0 \%$ 
Los 5 colores elegidos fueron escogidos para poder seguir una misma línea de comunicación con los Juegos Panamericanos y también porque creemos que las asociaciones de cada uno de estos colores tienen que ver con nuestros atributos diferenciales.

- Verde: color asociado con el crecimiento, ética y naturaleza. El atributo que se asocia con este color es que somos ecoamigables.

- Amarillo: color asociado con la calidez, alegría y positivismo. El atributo que se asocia con este color es que tenemos áreas para el deporte y la vida social, áreas donde podemos compartir momentos de alegría.

- Azul cielo: color asociado con la calma, descanso y libertad. El atributo asociado con este color es la libertad y calma que siente una persona al haber alcanzado el sueño de la vivienda propia.

- Azul: color asociado con la seguridad, credibilidad y profesionalismo. El atributo asociado con este color es que estamos respaldados por Besco una empresa segura, con vasta experiencia.

- Morado: color asociado con la imaginación y fantasía.

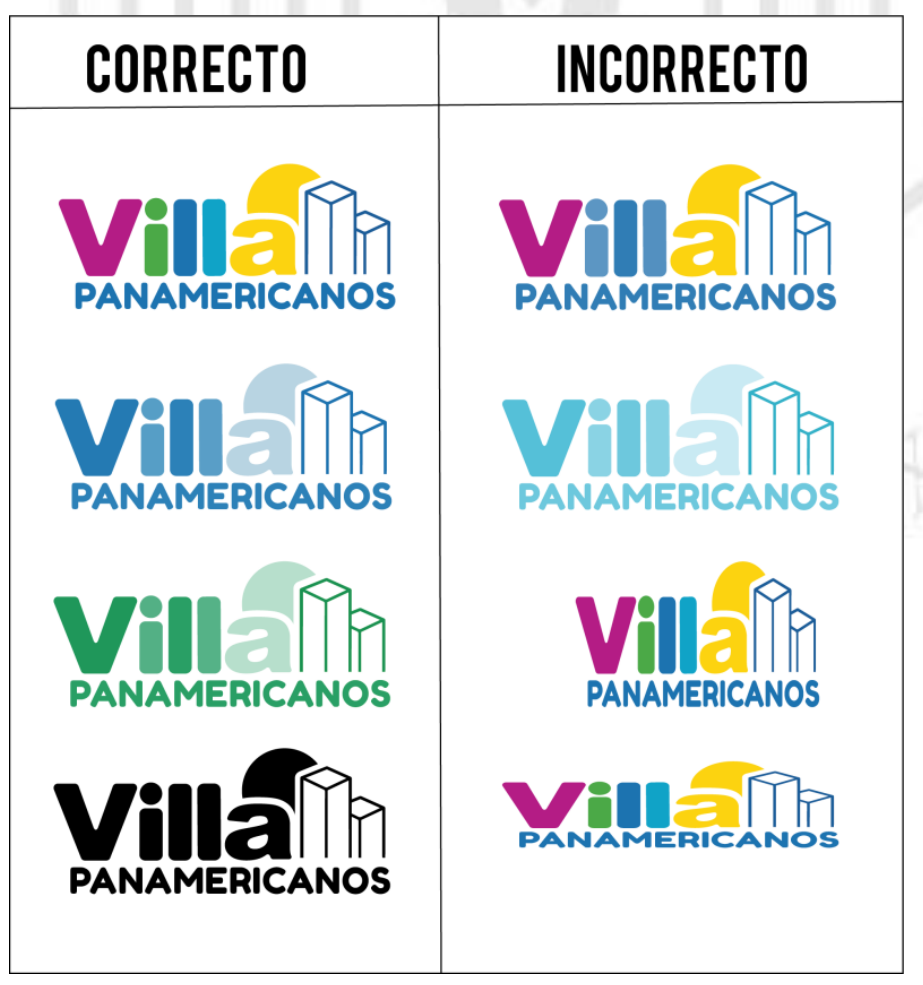

Ilustración 3: Usos incorrectos del logo. 


\subsection{Slogan:}

\section{"Vive tu meta"}

Nuestro slogan, hace referencia a los insights localizados en nuestra investigación que refuerzan la idea del cumplimiento del sueño de la casa propia y la realización personal. "Vive tu meta" significa poder disfrutar de los beneficios de haber logrado la adquisición de una vivienda propia en Villa Panamericanos.

\section{ESTRATEGIA CREATIVA}

\subsection{Concepto creativo}

Tomando el insight de nuestro público objetivo de que llegar a adquirir una vivienda propia es:

"Es un logro, tener una vivienda propia, darle un lugar seguro y estable a mis hijos"

"Para mí, significaría realizar un sueño"

"Sería almo mío, un logro porque es algo propio. Nadie me lo quita, ya lo logré por mi misma, base de esfuerzo"

- $\quad$ Nos basamos en el sueño de la casa propia que es una meta personal muy importante en la vida de todo ser humano, el dejar el hogar familiar donde muchos de los peruanos viven hasta después de haberse casado, es un paso a su independencia, significa dar y dejarles un legado a sus hijos.

- Este fuerte insight, en conjunción con nuestro producto, da vida a nuestro concepto "Vive tu meta". El concepto está fuertemente ligado al producto porque este está directamente relacionado con una actividad deportiva pues fue hecho para estos fines y las personas lo identifican de esta manera. Además uno de sus atributos diferenciales más importantes es contar con canchas multideportivas, este edificio está enfocado al deporte.

- Parte de nuestra comunicación será simbolizando a la vida como una competencia, donde la meta es la vivienda propia. El logro siempre será graficado de forma familiar. Para completar la idea se realizarán piezas gráficas de los miembros de la familia 
disfrutando de las áreas comunes y beneficios de Villa Panamericanos, viviendo su meta.

\subsection{Tono de la comunicación}

El tono de comunicación que usaremos será cercano a nuestro público objetivo, entendiendo el logro que es para ellos la vivienda propia. Emotivo porque usaremos la unión familiar y el logro alcanzado en conjunto.

Por otro lado en los medios de publirreportaje y contenidos en web, usaremos un tono de comunicación informativo con el objetivo de que nuestros clientes entiendan bien de que tratan los beneficios de mi Fondo Mivivienda y Bono Mivivienda Verde y el atributo de vivir en una vivienda ecoamigable.

\section{PLAN DE MEDIOS}

Villa Panamericanos estará listo para la venta en Enero del 2020, así que hemos propuesto un plan de lanzamiento de un mes y medio de duración y un plan de mantenimiento de 4 meses y medio. Iniciamos a mediados de diciembre, coincidiendo con las fechas de gratificación y sensación de bienestar en la población por fechas festivas.

\section{- Lanzamiento}

La etapa de lanzamiento tendrá como principal objetivo dar a conocer el producto y la marca. Confirmar lo que habían comunicado previamente los medios, que Villa Panamericanos, sería vendida luego de cumplir su función durante el periodo de los Juegos Panamericanos y Parapanamericanos. Debemos lograr en la comunicación que los atributos diferenciales de nuestro producto puedan posicionarse adecuadamente en la mente de nuestro público objetivo.

\section{- Mantenimiento}

La etapa de mantenimiento tendrá como principal objetivo reforzar el posicionamiento de la marca y continuar captando a nuevos clientes potenciales recaudando su información para nuestra base de datos y así mismo, incentivar la compra del producto. Mantendremos nuestra presencia en los medios donde podemos tener una interacción directa con el cliente potencial; medios digitales tales como Adwords y Facebook. 
Ver detalle de presupuesto en:

https://drive.google.com/open?id=1n6A4Hv0PHW5yRWg016pxs5i8rIwPSUI5

Nuestra propuesta incorpora un mix de ATL, BTL Y digital, donde cada medio tendrá diferentes propósitos.

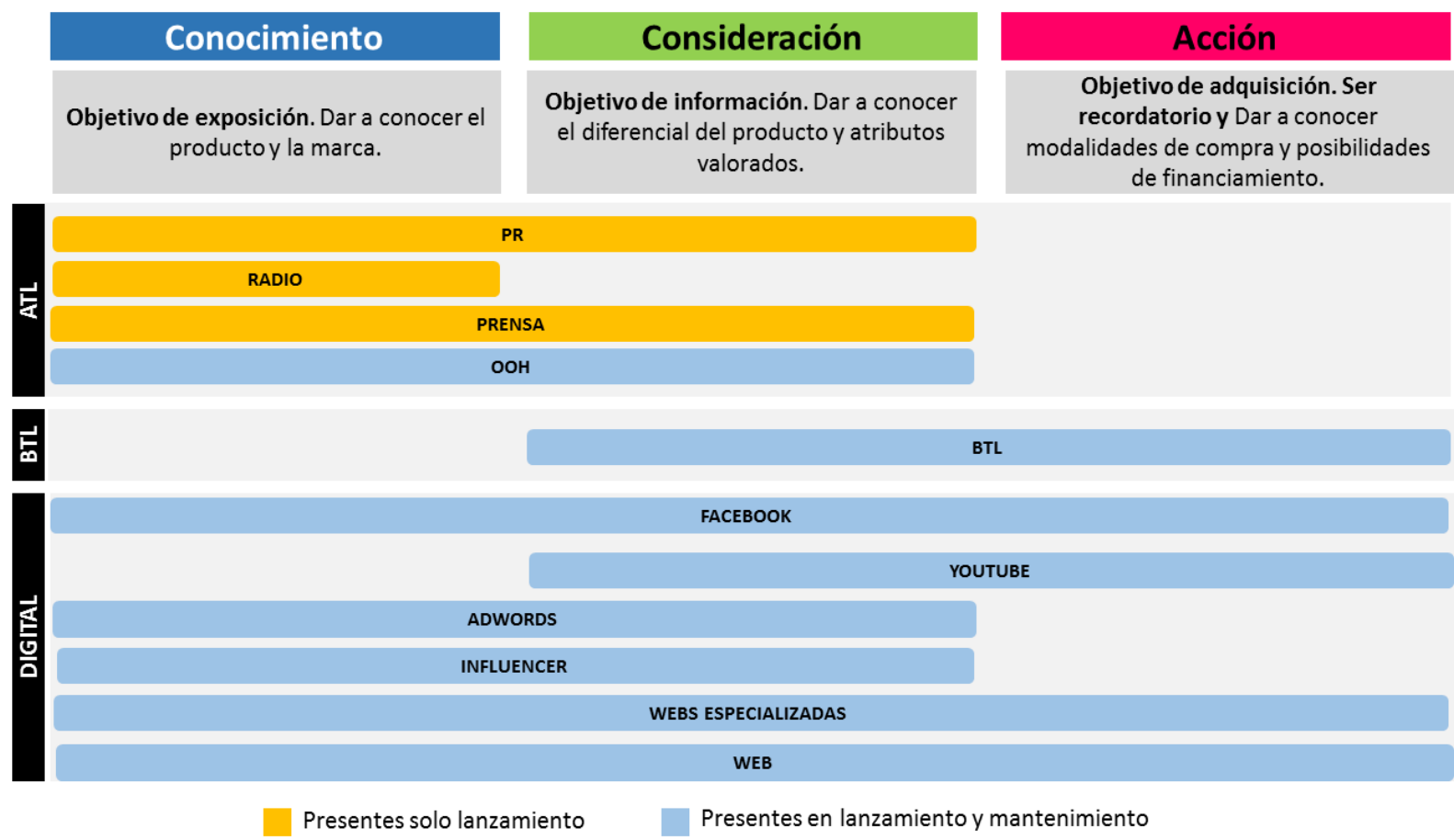

Figura 28: Objetivo de medios Fuente: Elaboración propia

\subsection{Radio}

CONSUMO DE MEDIOS TRADICIONALES

\begin{tabular}{|c|c|c|c|c|c|}
\hline & पाI & 를 & . & $=$ & 틀 \\
\hline & $\begin{array}{c}\text { TV Abierta } \\
\text { nacional }\end{array}$ & Radio & PDV & оОН & $\begin{array}{c}\text { Periódicos c } \\
\text { revistas }\end{array}$ \\
\hline ALTA FRECUENCIA & $85 \%$ & $66 \%$ & $66 \%$ & $65 \%$ & $62 \%$ \\
\hline $\begin{array}{l}\text { Diario } \\
\text { Al menos una vez } \\
\text { por semana }\end{array}$ & $64 \%$ & $21 \%$ & $38 \%$ & $21 \%$ & $34 \%$ \\
\hline $\begin{array}{l}\text { Al menos una vez al } \\
\text { mes } \\
\text { Nunca }\end{array}$ & $\frac{10 \%}{7 \%}$ & & $16 \%$ & $18 \%$ & $\begin{array}{l}19 \% \\
19 \%\end{array}$ \\
\hline
\end{tabular}

Figura 29: Consumo de Medios Tradicionales. Fuente: IPSOS. 


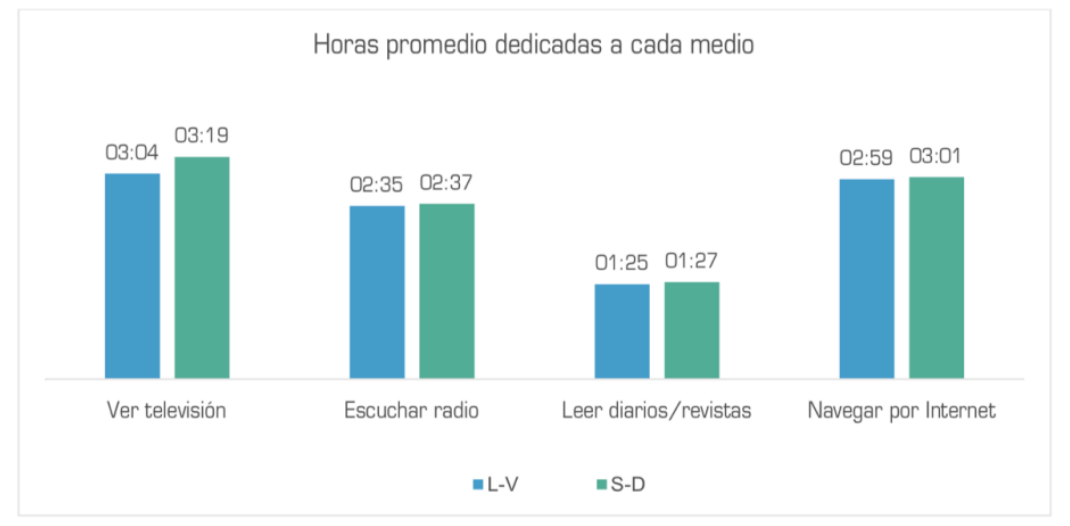

Al preguntar a los entrevistados/as por los programas de TV más vistos, mencionaron en primer lugar a "América Noticias Primera Edición" (२०.4\%), seguido de "9० Matinal" (18.२\%), "Esto es Guerra - EEG" (13.3\%), "América Noticias Edición Central" (11.9\%), y "ATV Noticias Edición Central" (10.1\%).

Figura 30: Horas promedio dedicadas a cada medio. Fuente: Concor TV

Sustento: La radio es el segundo medio de mayor consumo en Lima (66\%), quienes la consumen en un promedio de 2 horas diarias a más. Observamos que tiene mayor presencia en los NSE C, D y E y entre las personas de 25 a 44 años. El mayor consumo se presenta de lunes a viernes y los fines de semana el $21.8 \%$ de los radioescuchas no consumen el medio.

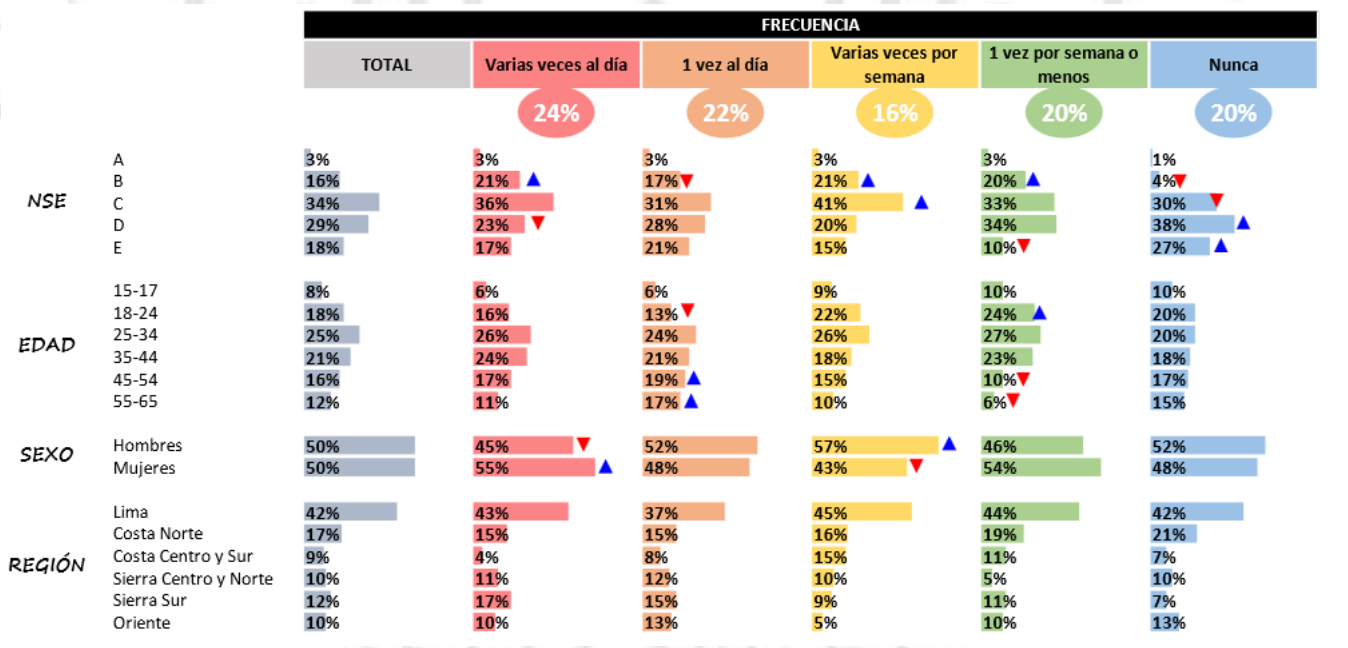

Figura 31: Perfil de consumidores Radio. Fuente: Ipsos 2018

\section{Emisoras:}

La elección de emisoras en las que vamos a anunciar está en base al número de audiencia de nuestro segmento, son las preferidas del NSE C. Además escogemos los horarios que tienen mayor escucha según un estudio de Kantar Ibope Media - Target Group Index (TGI) del 2019, donde afirman que la mayor audiencia es de lunes a viernes de 9am a $12 \mathrm{~m}$ y el segundo de 6am a 9 am en los mismos días. 
- RPP: Rotativa del Aire (6am-8am)

- Moda: El Show de Carloncho (10 am - $12 \mathrm{~m})$

- La Karibeña: La Ruleta Karibeña (9 am - 12m)

Tiempo: 5 veces al día de lunes a viernes durante el mes de enero (330 avisos en total)

Costo total: S/ 157,080

Duración: 30 segundos

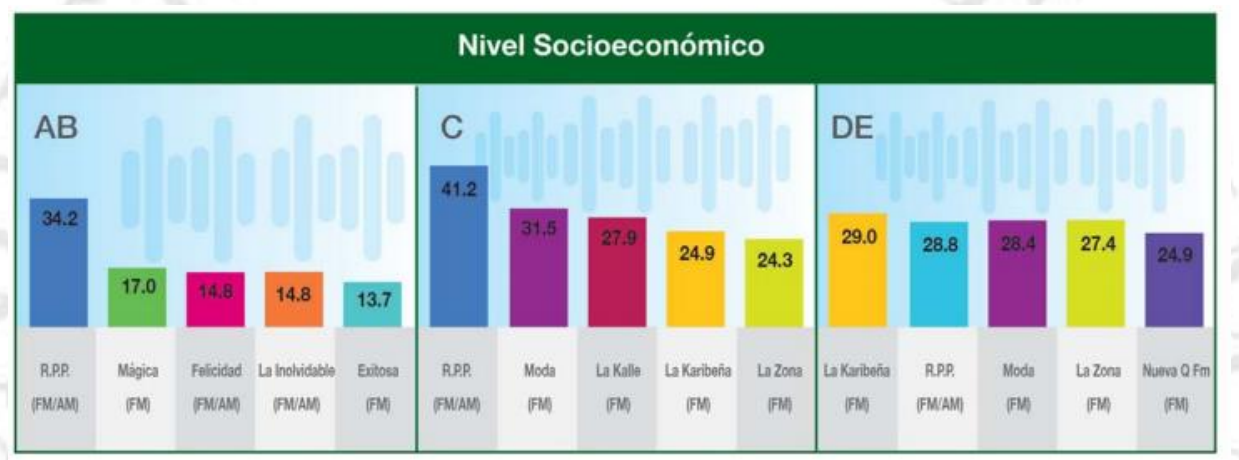

Figura 32: Top five emisoras, según NSE. Fuente: CPI 2018

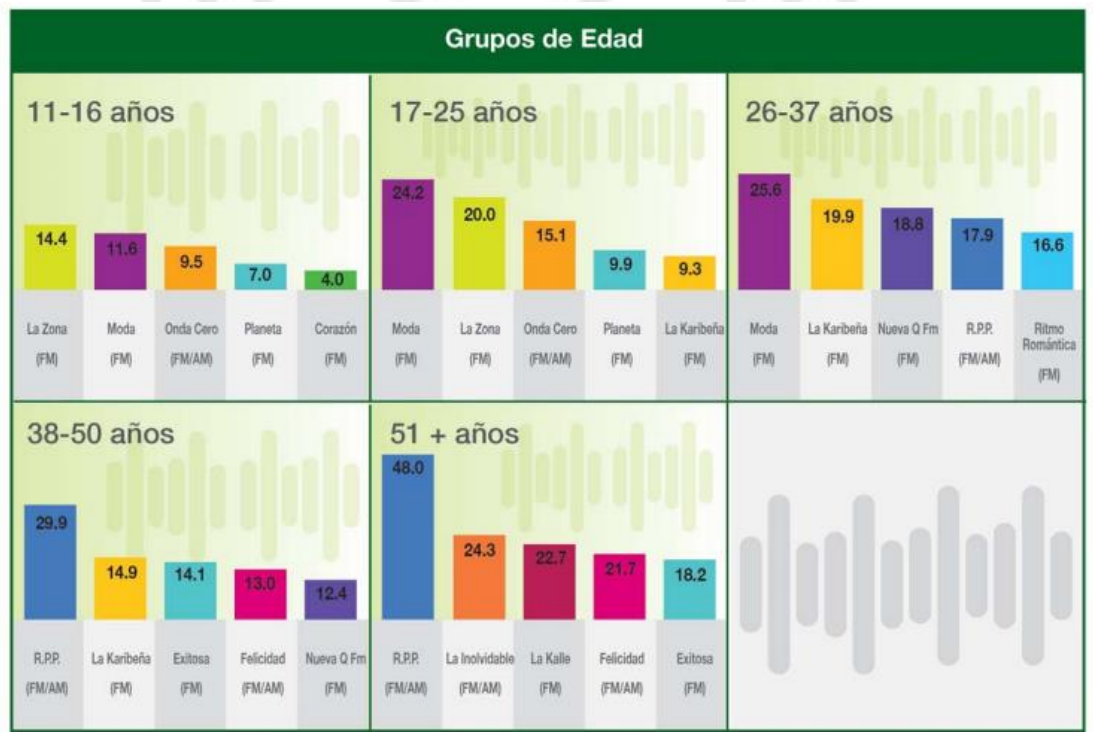

Figura 33: Top five emisoras, según grupo de edades. Fuente: CPI 2018 


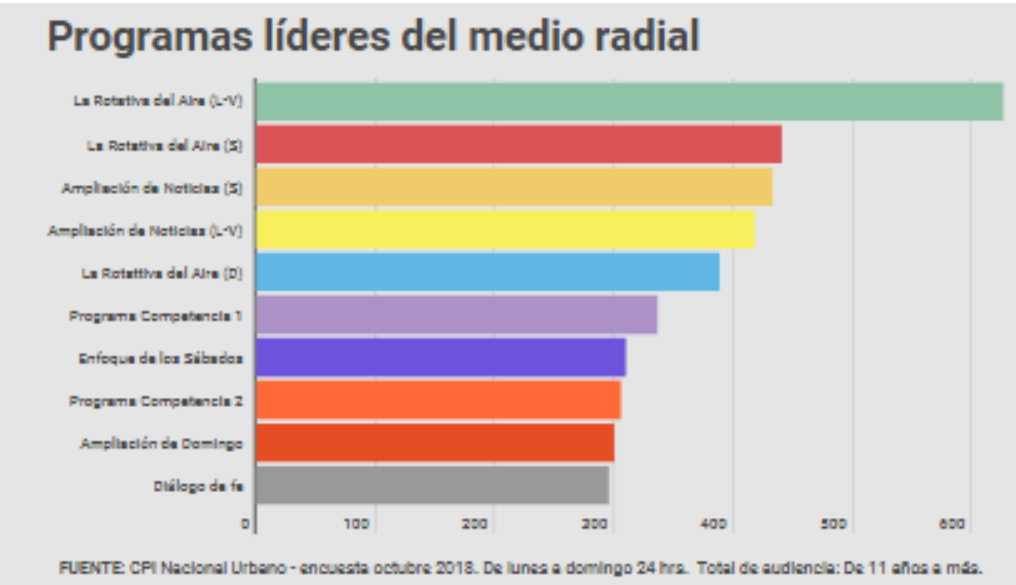

Figura 33: Audiencia y programas líderes en RPP. Fuente: CPI Nacional Urbano

Guión de Radio:

Interlocutor: Sr. Raúl ¿qué es para usted vivir la meta?

Sr. Raúl: para mi vivir mi meta, es que mis hijos duerman en un lugar seguro.

Interlocutor: Sra. Juana ¿qué es para usted vivir la meta?

Sra. Juana: Para mi vivir la meta es que mis hijos disfruten jugando en un ambiente seguro y crezcan haciendo deporte

Interlocutor: Sra. María ¿qué es para usted vivir la meta?

Sra. María: Para mi vivir la meta es vivir en un ambiente sano y y moderno.

Interlocutor: La señora María, el señor Raúl y la señora Juana, saben que pueden alcanzar y vivir su meta del departamento propio en Villa Panamericanos. Tú también puedes lograrlo con el crédito Mivivienda y Bono verde, estás más cerca de ¡Vivir tu meta!

\subsection{Prensa}

Sustento: Observamos que los medios impresos tienen mayor consumo en el NSE CD y entre las personas de edades de 25 a 44 años, esta data calza con los datos de nuestro público objetivo. Por otro lado, vemos que el periódico más leído es el Trome que cuenta con más de 3,900 lectores por semana en Lima Metropolitana. 


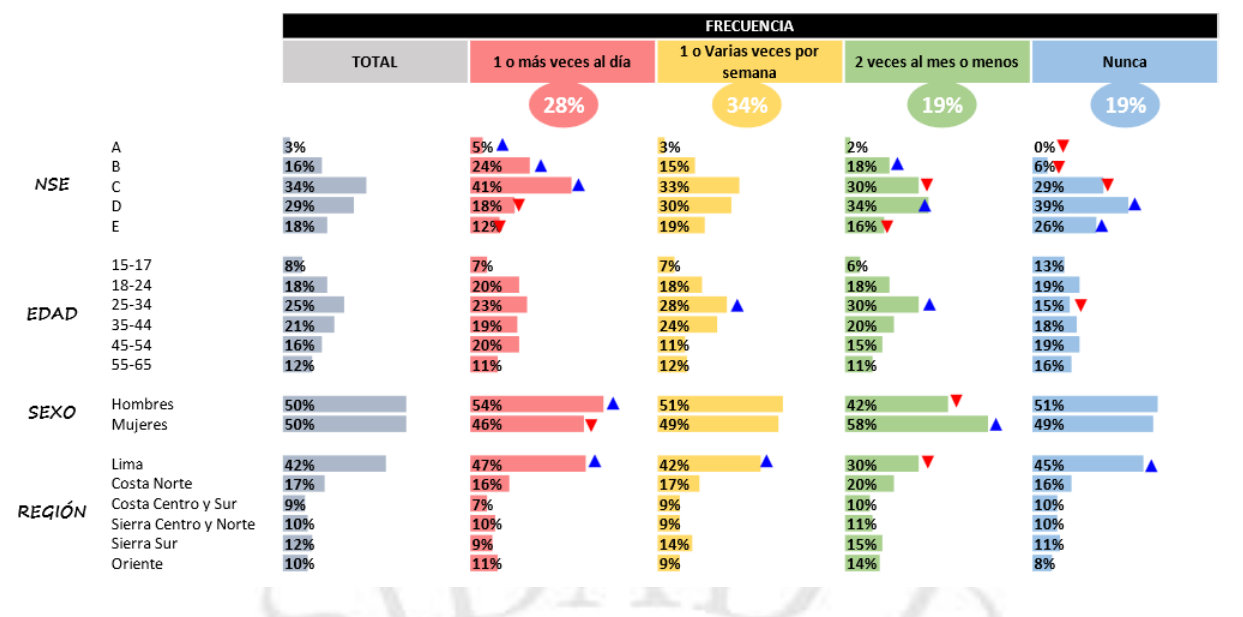

Figura 34: Perfil de consumidores de periódicos impresos. Fuente: Ipsos 2018

Periódico: Trome

Formato: $6 \times 12 \mathrm{~cm}$

Tiempo: una vez por semana, día miércoles (5 veces) todo el mes de enero.

Costo total: S/. 50,000

$\underline{\text { Pieza comunicacional: }}$
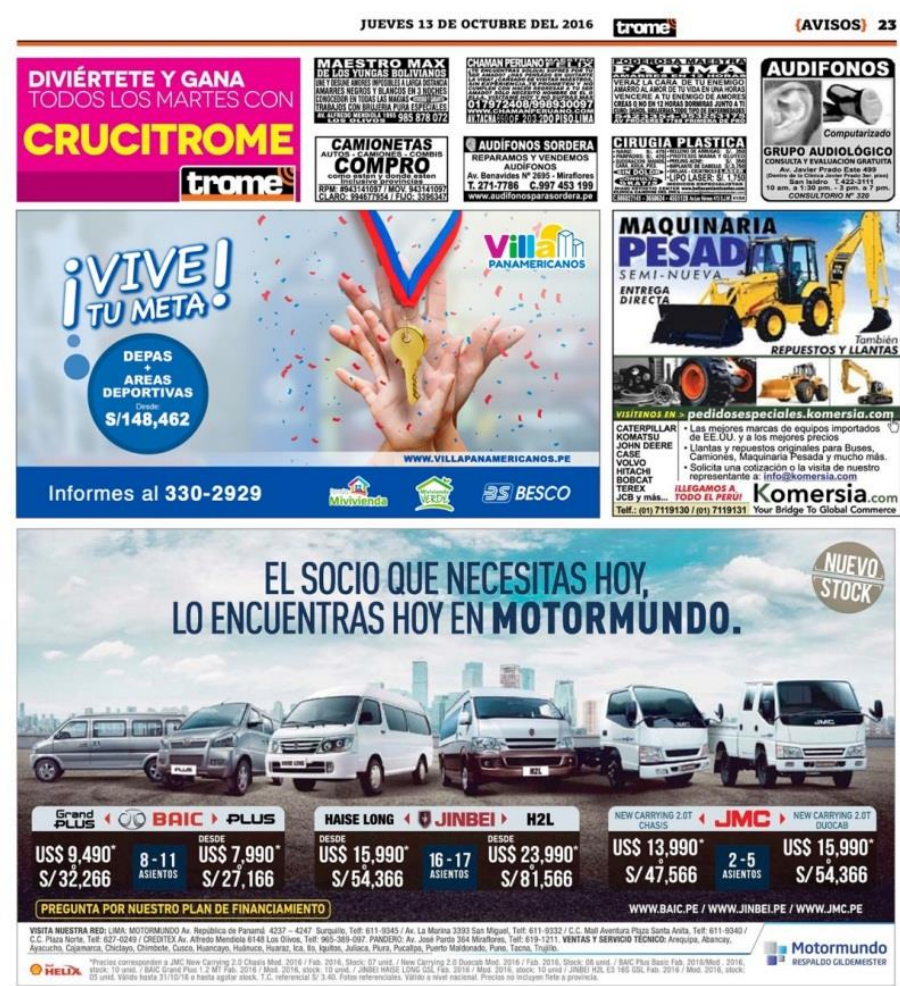

Ilustración 4: Ejemplo de anuncio en prensa 


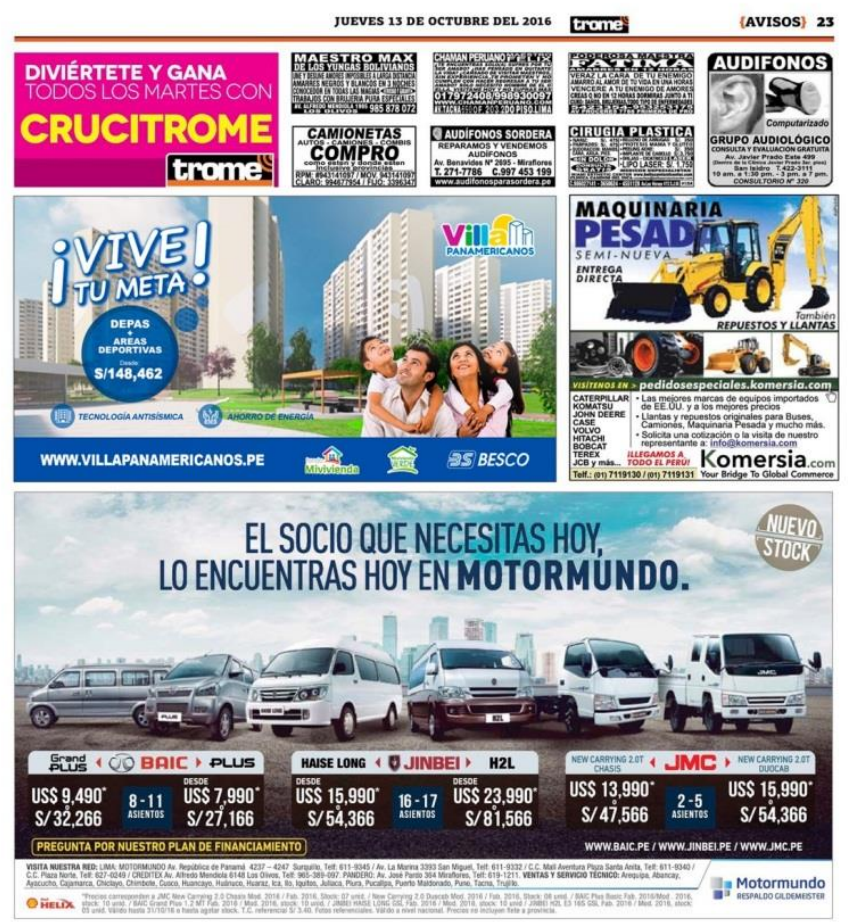

Ilustración 5: Ejemplo de anuncio en prensa

\section{3. $\mathrm{OOH}$}

$\underline{\text { Sustento: }}$ Las vallas publicitarias tienen la fortaleza de permanecer las 24 horas del día con nuestra publicidad, exposición constante esto garantiza tener un mayor alcance. Además e comparación con otros medios tradicionales, resulta mucho más conveniente por los precios.

Datos: La Línea 1 del Metro de Lima transporta alrededor de 355 mil personas diariamente, desde Villa el Salvador hasta San Juan de Lurigancho.

Agencias: Punto visual, OOH Publicidad en Exteriores

Formato: Valla en la Panamericana (8 x 3 metros), Valla en Línea 1 del Metro de Lima (4x 2 metros)

Tiempo: Durante 3 meses entre la campaña de lanzamiento y mantenimiento. Desde enero 2020 hasta marzo 2020.

Costo total: S/.74,360

Pieza comunicacional: Vallas en la vía Panamericana Sur: En estas vallas estará nuestro banner publicitario, donde se muestra a una familia cruzando la meta (su departamento propio). 


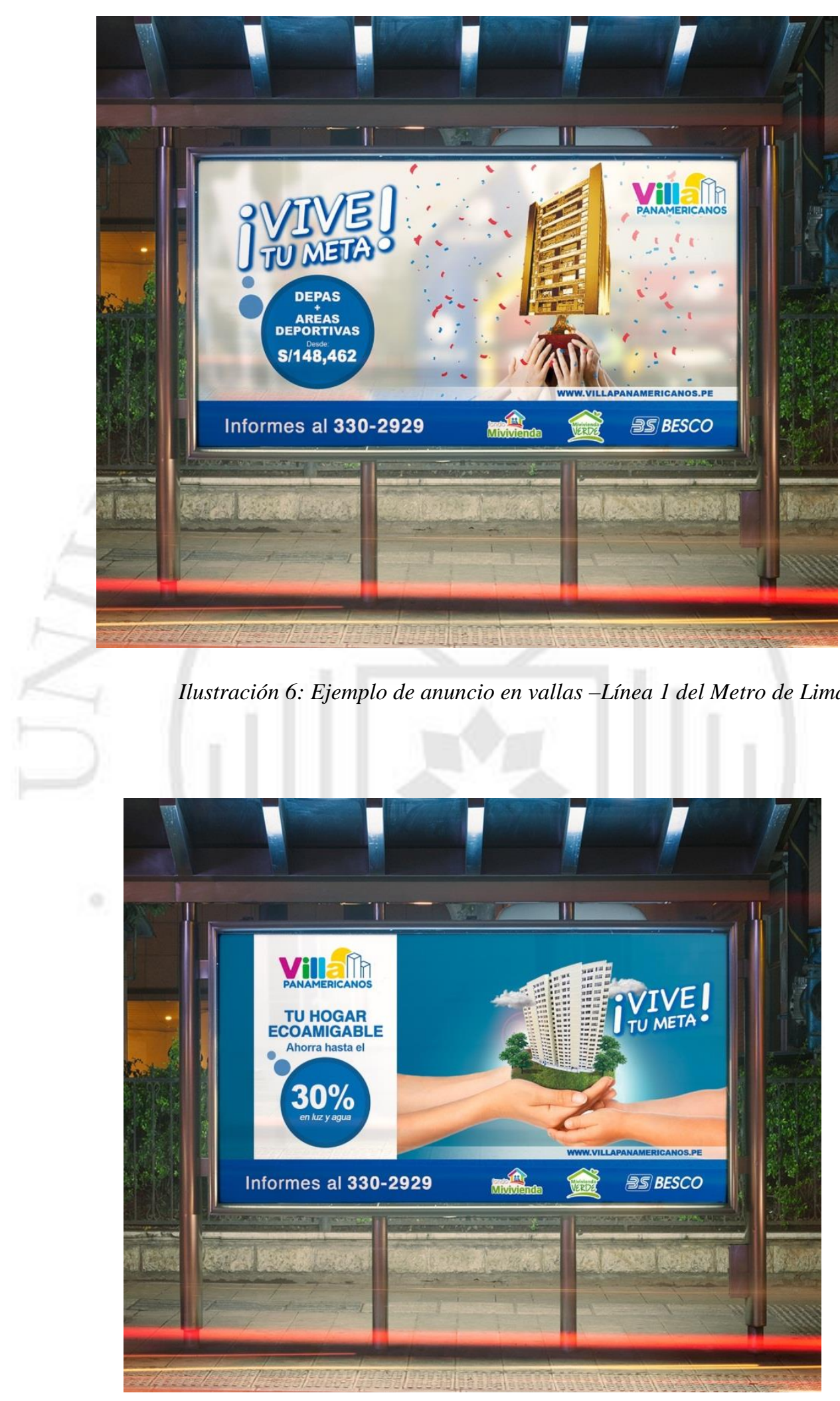

Ilustración 7: Ejemplo de anuncio en vallas -Línea 1 del Metro de Lima 


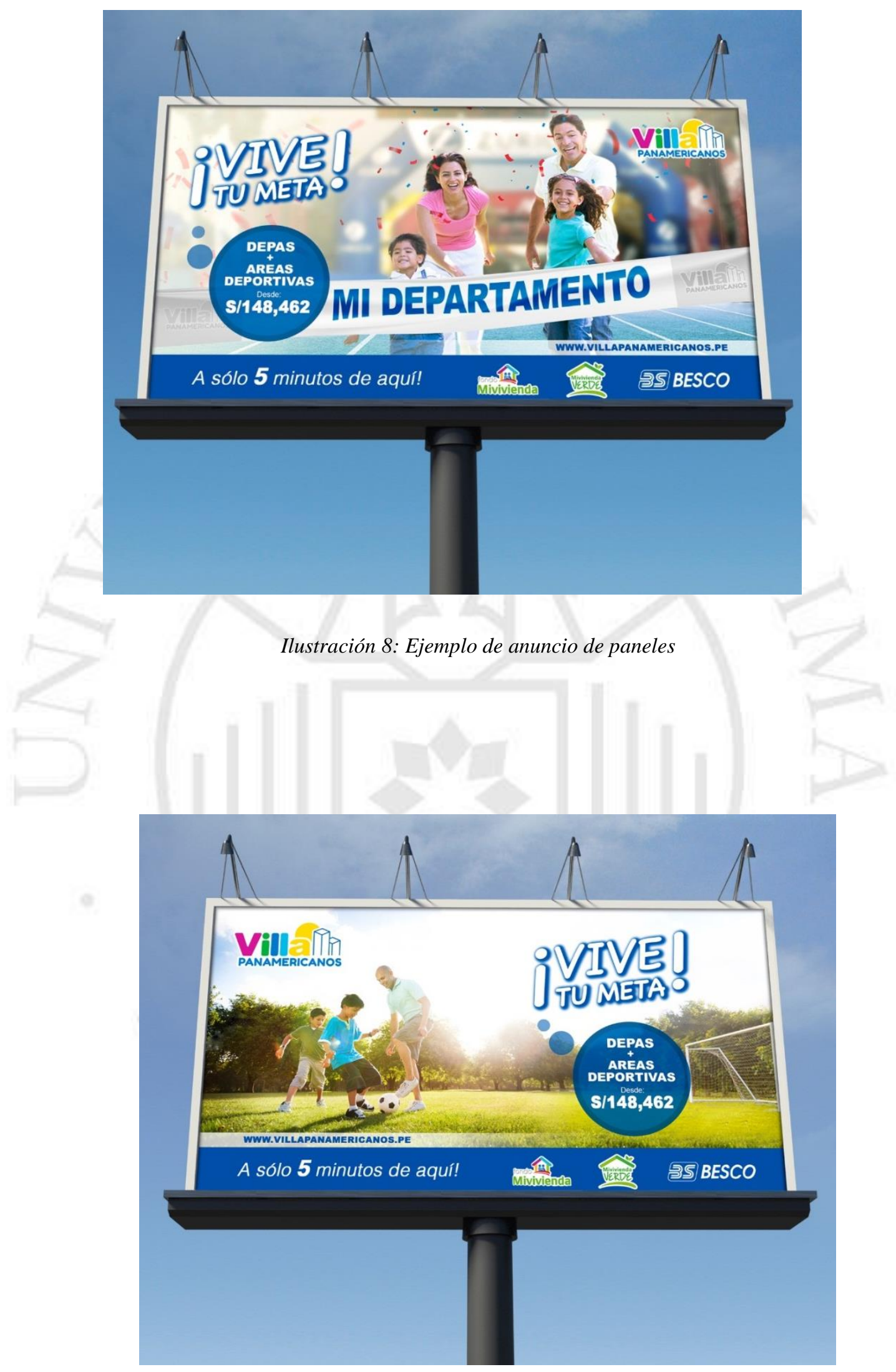

Ilustración 9: Ejemplo de anuncio en vallas 


\subsection{BTL}

\section{- Presencia en Centros Comerciales:}

Sustento: Tener presencia con un stand en los malls escogidos nos acerca a nuestro público objetivo y les evita la fatiga de trasladarse hasta el proyecto para tener mayor información. De esta manera podemos absolver dudas, recaudar sus datos y llamar la atención con el material propuesto y merchandising.

Formato: 3 x 2 metros

Tiempo: Los 6 meses que durará nuestras campañas de Lanzamiento y Mantenimiento. Desde Enero 2020 hasta Junio 2020

Ubicación: Mall del Sur, Real Plaza Villa María del Triunfo y Mall Santa Anita Costo total: S/. 77,037

Pieza comunicacional: Activaciones en los principales malls de Lima, de mayor concurrencia por nuestro público objetivo. En estos stands tendremos grandes pantallas para que nuestros clientes potenciales puedan hacer un recorrido 3D por los departamentos, además colocaremos un espacio para que puedan apreciar el material de los acabados. El material informativo que nos apoyará será un brochure con la información requerida y fotos atractivas.

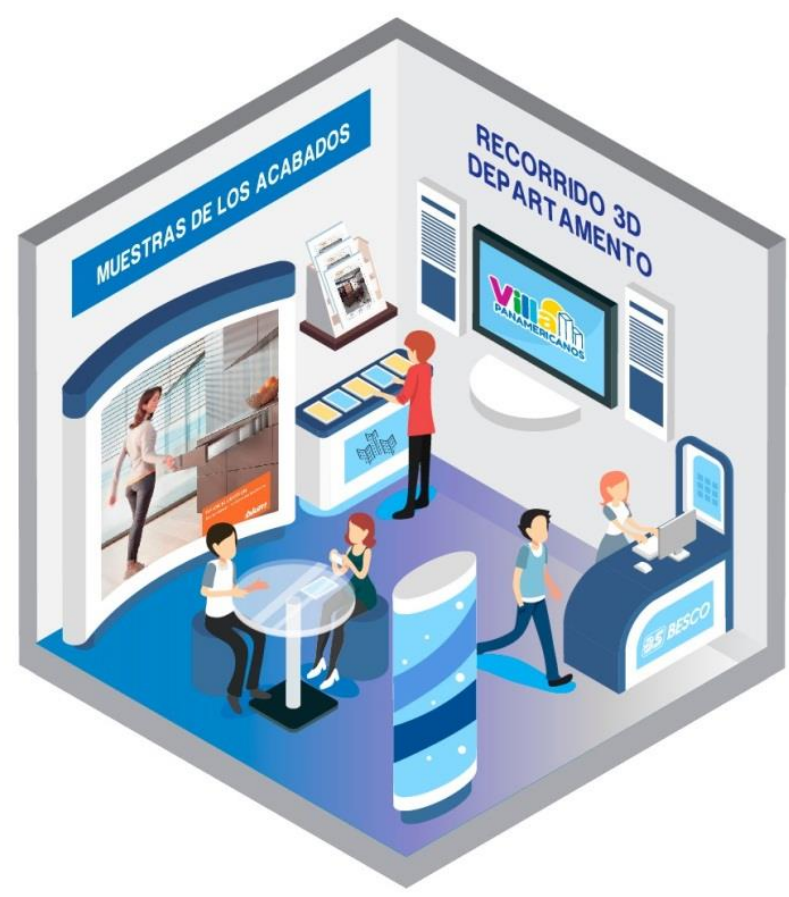

Ilustración 10: Ejemplo stand en centros comerciales. 


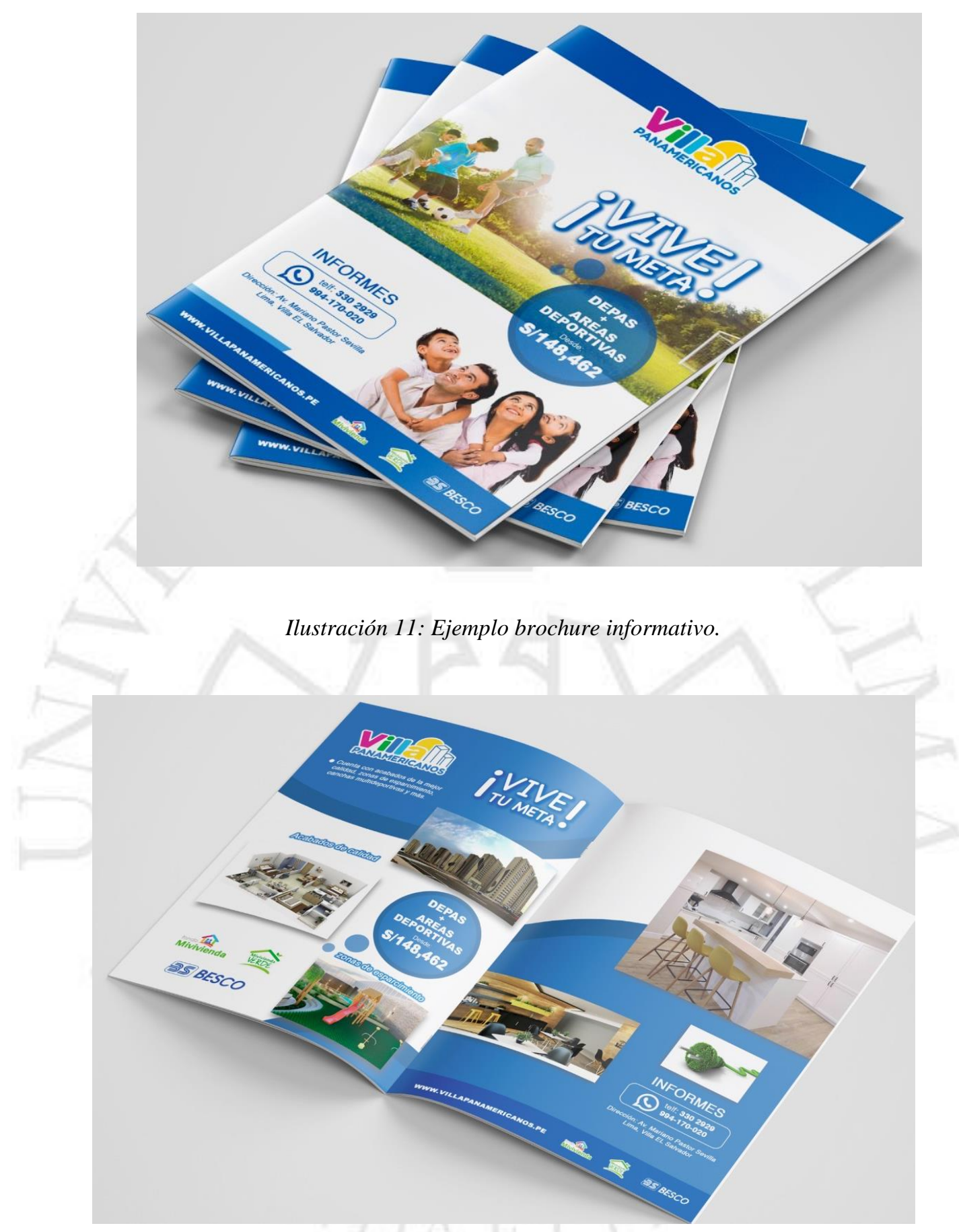

Ilustración 12: Ejemplo de brochure informativo.

\section{- Besco Móvil}

Sustento: La empresa Besco utiliza un vehículo "Besco móvil" para llegar a sus clientes potenciales en diferentes puntos de la ciudad.

Acción: El Besco Móvil irá a todos lugares donde están nuestros clientes potenciales para brindarles la información requerida; brochures, merchandising, entre otros.

Locaciones: Diversos mercados durante la semana, Centros Comerciales los fines de semana 
Tiempo: 6 meses

Costo total: S/. 0.00

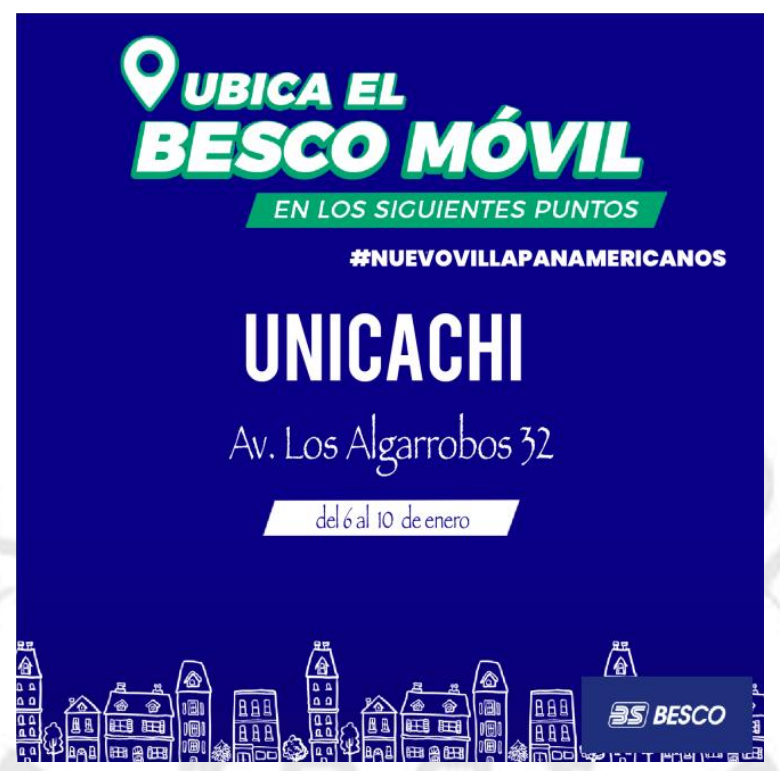

Figura 35: Ejemplo de comunicación del Besco Móvil. Fuente: Besco

\subsection{Digital}

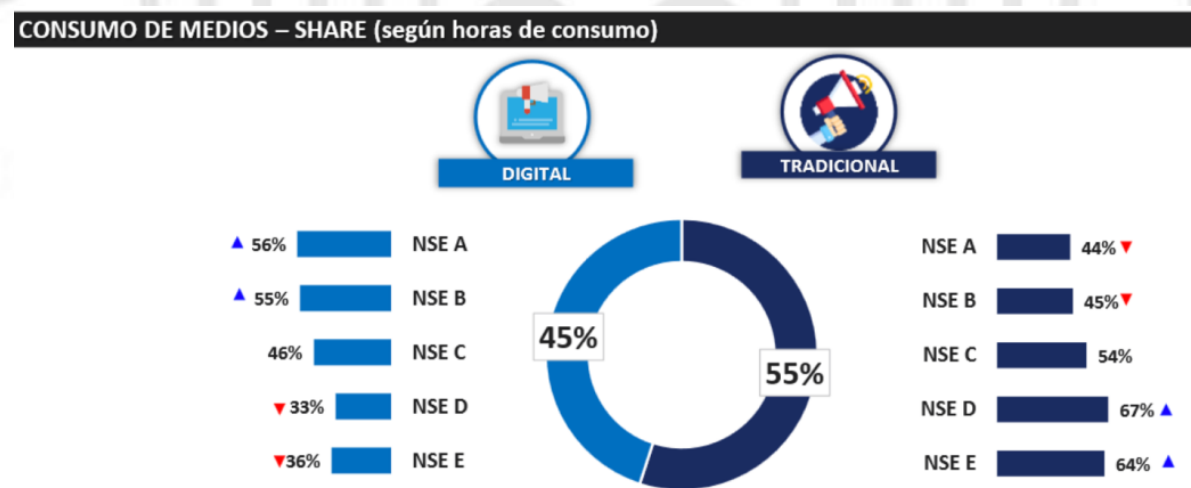

"Poco más de la mitad del tiempo de consumo se da en los medios tradicionales"

Figura 36: Horas promedio dedicadas a cada medio. Fuente: IPSOS

Sustento: El consumo de los medios digitales está en aumento y cada vez más cerca del consumo de medios tradicionales. En este cuadro podemos ver que abarca el $45 \%$ de share en comparación con los tradicionales y en nuestro público objetivo (NSE C) el $46 \%$ lo consume, acercándose al tradicional que tiene un 54\%. El tiempo que dedican en este medio 
es 3 horas de lunes a domingo. El 68\% utiliza Internet para visitar redes sociales tales como Facebook, YouTube y realizar búsquedas por medio de Google.

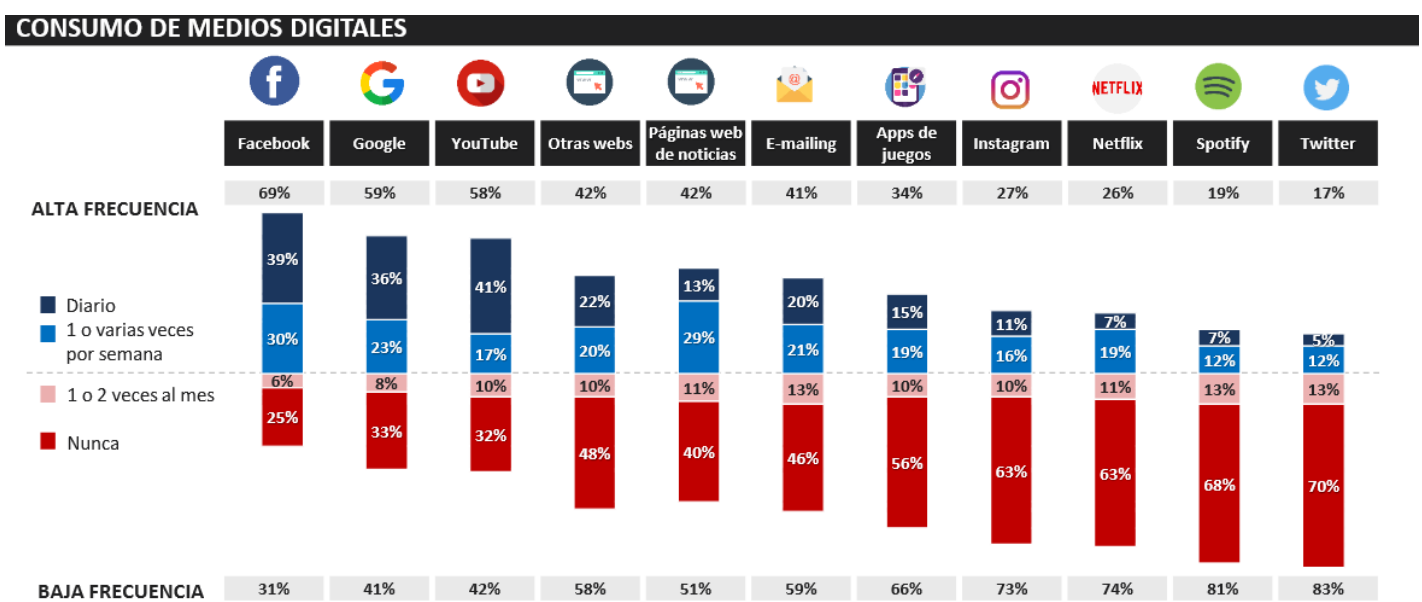

Figura 37: Consumo de Medios Digitales. Fuente: IPSOS.

La segunda actividad que realizan es chatear por Whatsapp y Facebook Messenger. Por los motivos descritos hemos considerado contar con un plan de medios digitales, integrando redes sociales, adwords (web), remarketing y Whatsapp Business.

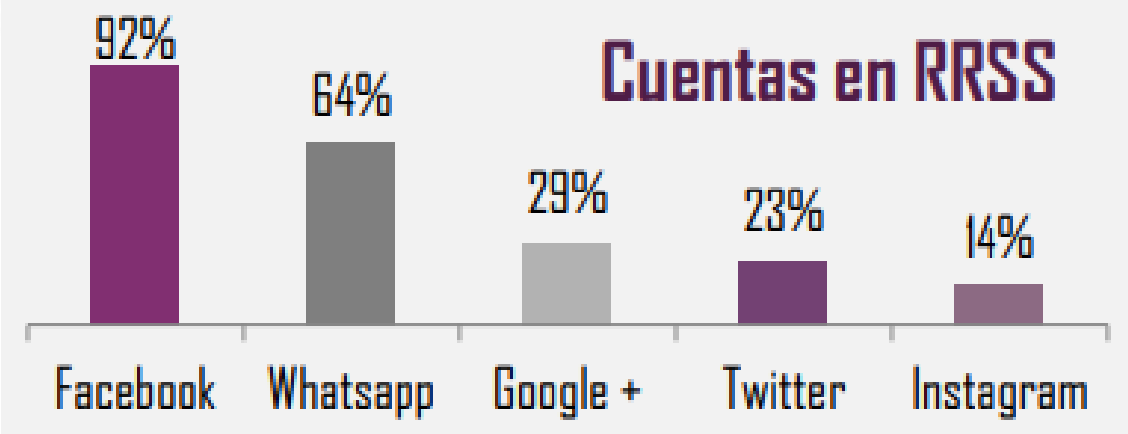

Figura 38: Cuentas en Redes Sociales. Fuente: Datum

\subsubsection{Redes Sociales}

Descripción: La red social que hemos seleccionado es Facebook ya que es una de las redes sociales de mayor consumo en el NSE C; sin embargo, con el fin de tener mayor tráfico creemos conveniente tener una alianza con Besco quienes ya cuentan con un fan page con 
más de 100 mil fans, con publicaciones diarias y campañas pagadas de sus proyectos en venta. Cada uno de sus proyectos tiene un nombre especial y es comunicado de una manera bastante parecida entre ellos, usando la misma persona como imagen de campaña y el mismo slogan.

Lo que proponemos es que por medio del fan page de Besco se realice una campaña previa para el proyecto de Villa Panamericanos, publicidad que derive al fan page que se creará exclusivo para Villa Panamericanos.

\section{- Campaña en Facebook:}

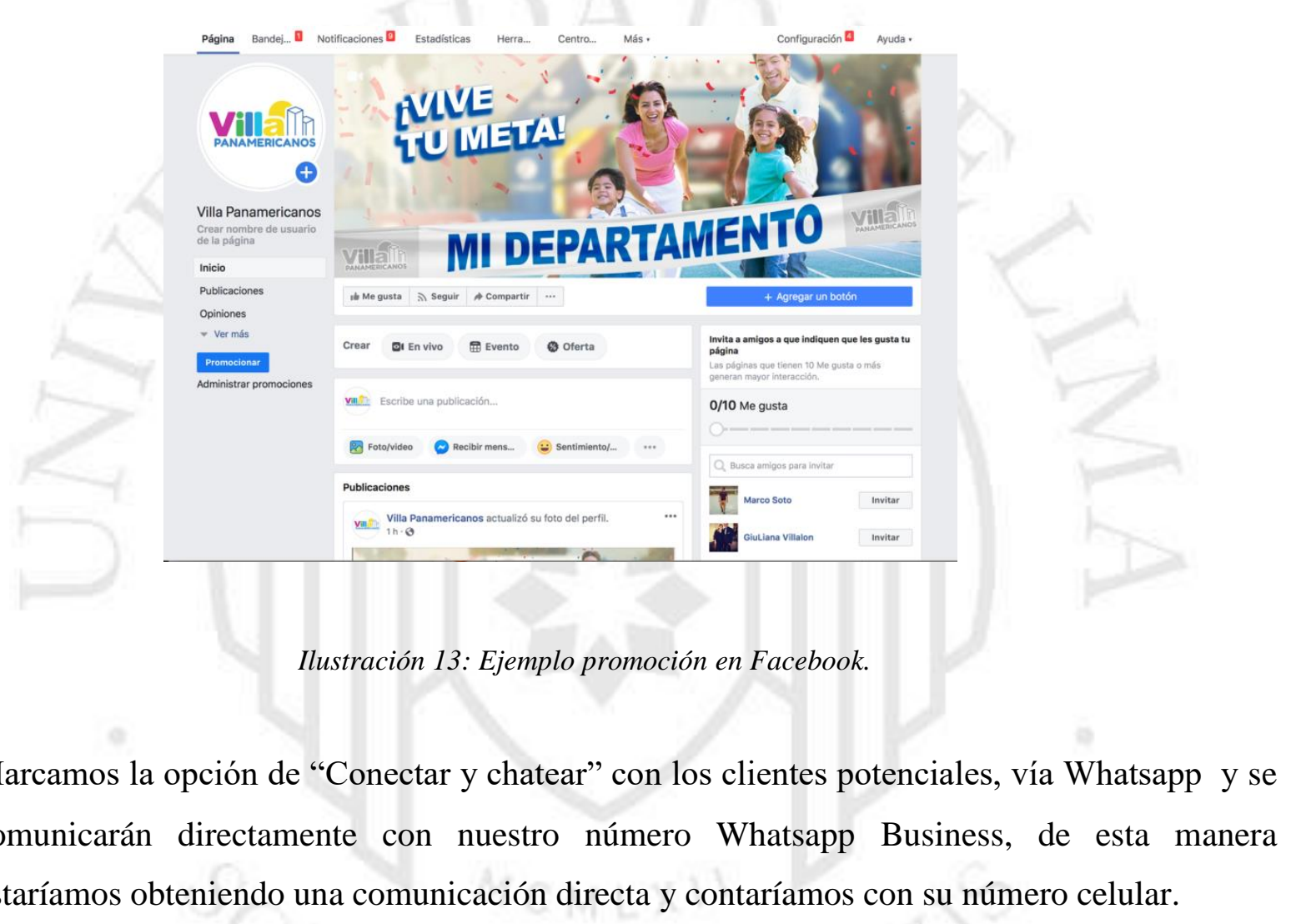

Segmentación: Hombre y Mujeres de 25-40 años en la ciudad de Lima.

Tiempo: Los 6 meses que durará nuestras campañas de lanzamiento y mantenimiento. Desde enero 2020 hasta junio 2020.

Costo total: S/. 14,1960 soles

Pieza comunicacional: 


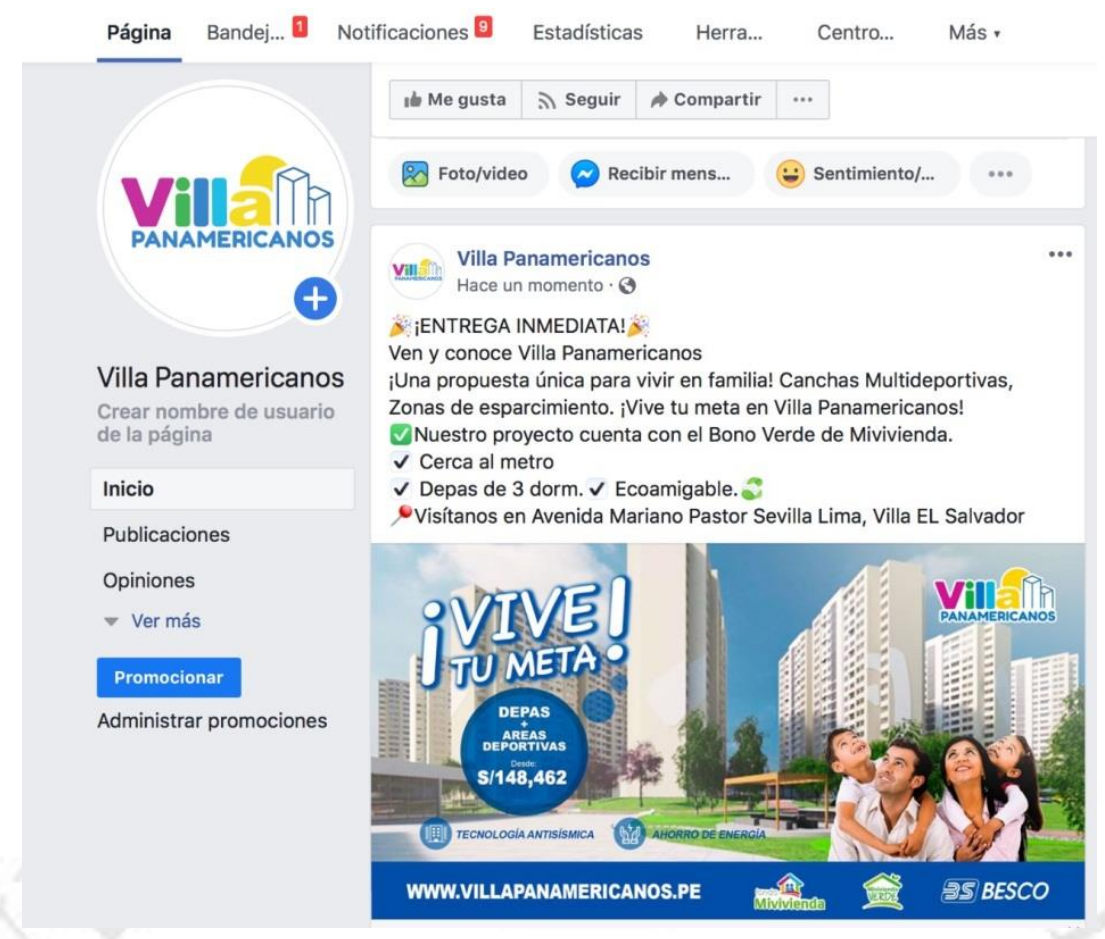

Ilustración 14: Ejemplo de PPL en Facebook.

Adicionalmente trabajaremos bajo el esquema de remarketing para poder captar a aquellos que ya interactuaron con nosotros. La idea es seguir incentivándolos a que pidan información del proyecto y posteriormente conviertan.

Para cumplir los objetivos de Facebook a lo largo de la campaña, hemos planeado la publicación de contenidos a seguir.

\begin{tabular}{|c|c|}
\hline OBJETIVO & CONTENIDO \\
\hline Conocimiento & $\begin{array}{l}\text { - ¿Por qué escoger Villa Panamericanos? } \\
\text { - Fotos de deportistas disfrutando las instalaciones de Villa } \\
\text { Panamericanos. } \\
\text { - Recorrido virtual 3D de instalaciones de departamentos para poder } \\
\text { tener una idea clara de la distribución y las diferencias entre los } \\
\text { dos tipos de departamentos. } \\
\text { - Recorrido virtual de las canchas multideportivas y áreas comunes. }\end{array}$ \\
\hline Consideración & $\begin{array}{l}\text { - ¿Cómo aplicar al Fondo Mivivienda? } \\
\text { • ¿Cómo obtener un crédito hipotecario? ¿Qué documento se } \\
\text { necesitan? } \\
\text { • ¿Cómo obtener el Bono Verde? }\end{array}$ \\
\hline
\end{tabular}




\begin{tabular}{|c|c|}
\hline & $\begin{array}{l}\text { - ¿Qué significa edificación verde? } \\
\text { - ¿Qué significa el grado } 2 \text { ? } \\
\text { - Piezas informativas de la reducción de consumos en servicios por } \\
\text { ser una construcción ecoamigable e información (video tutorial) de } \\
\text { cómo acceder al crédito Mivivienda y el Bono verde. } \\
\text { - Noticias de actualidad acerca de las construcciones ecosostenibles. }\end{array}$ \\
\hline $\begin{array}{l}\text { Adquisición } \\
\begin{array}{l}\text { I } \\
\text { n } \\
\text { s } \\
\text { t }\end{array}\end{array}$ & $\begin{array}{l}\text { - Videos testimoniales de deportistas que ya viven en los } \\
\text { departamentos. } \\
\text { - Videos testimoniales, personas reales que hayan adquirido el } \\
\text { departamento y cuenten su positiva experiencia. } \\
\text { - Inscripción en línea, llenado de datos y envío hacia el landing page } \\
\text { para proceder a las cotizaciones. } \\
\text { - Compartir fotos de las familias del momento de adquisición de su } \\
\text { departamento. }\end{array}$ \\
\hline
\end{tabular}

gram

Decidimos no utilizar Instagram como plataforma de publicidad porque vemos que su uso está concentrado en el NSE A y B. No sería una herramienta digital de gran uso de nuestro público objetivo.

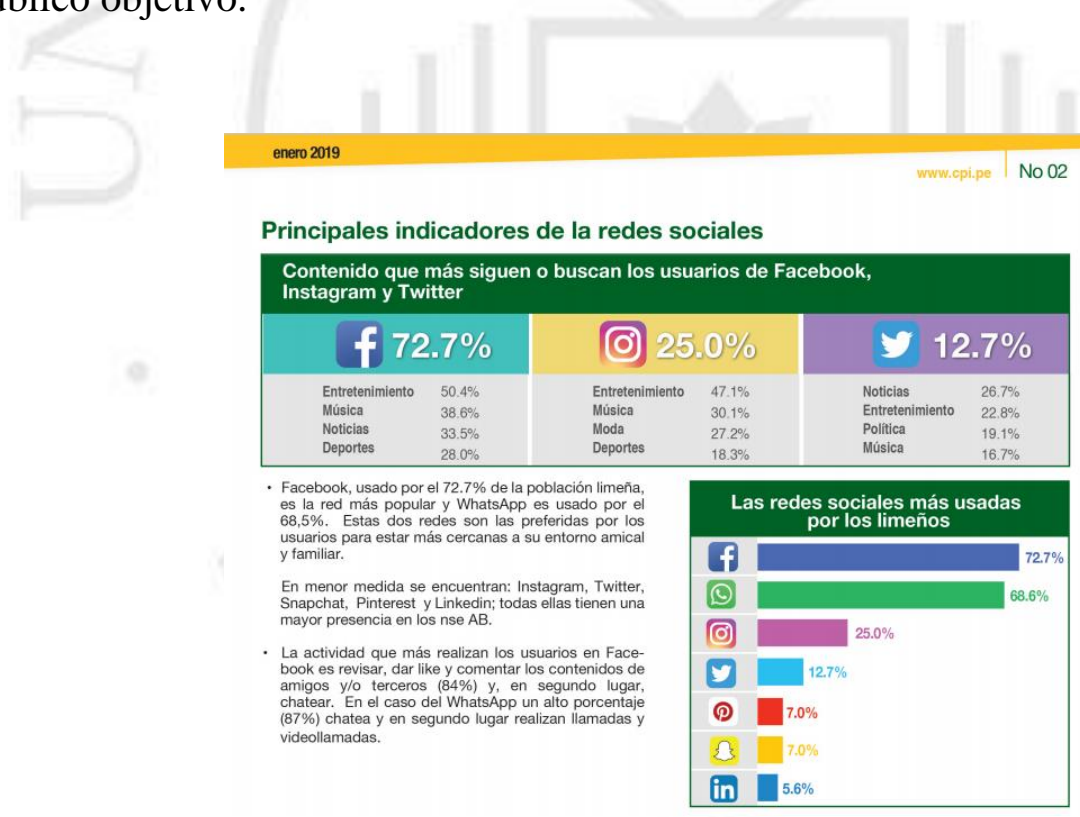

Figura 39: Principales indicadores de redes sociales. Fuente: CPI 2019

Sin embargo, creemos importante que debemos tener presencia en esta a través de una cuenta sin publicidad, ya que es una plataforma digital que tiene un crecimiento excesivo y no descartamos utilizarla para campañas futuras. Por mientras compartiremos, el mismo contenido que tenemos en 

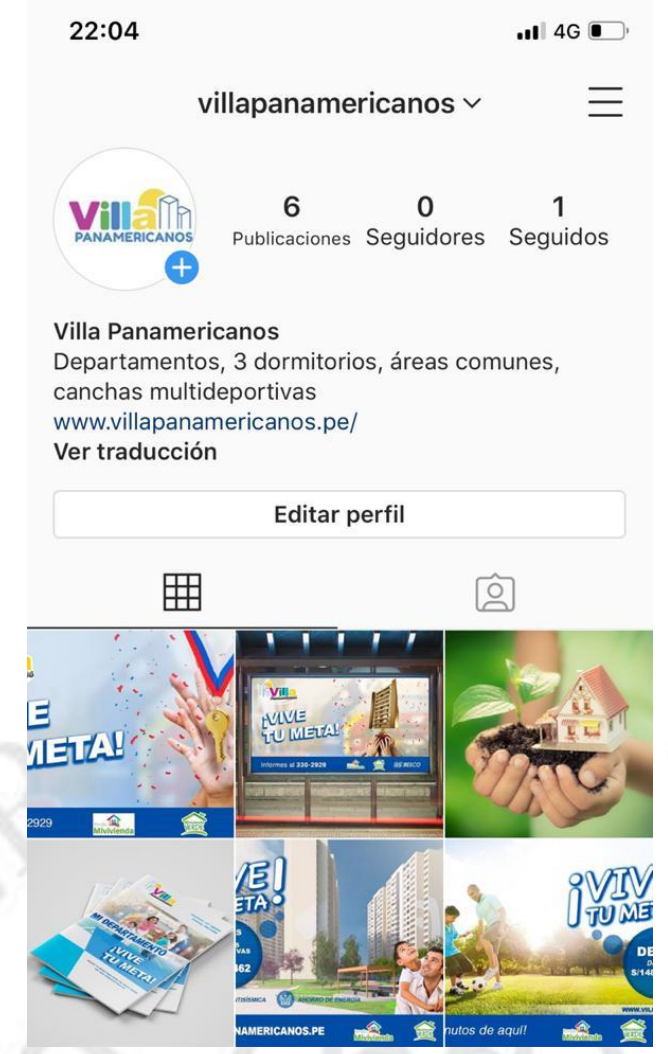

Figura 35: Social Media Audiences: Quarterly Growth. Fuente: Hootsuite - we are social

Facebook. En el siguiente cuadro podemos observar que en el último año Instagram ha tomado mayor protagonismo, similar al de Facebook, caso contrario el de Twitter y Snapchat.

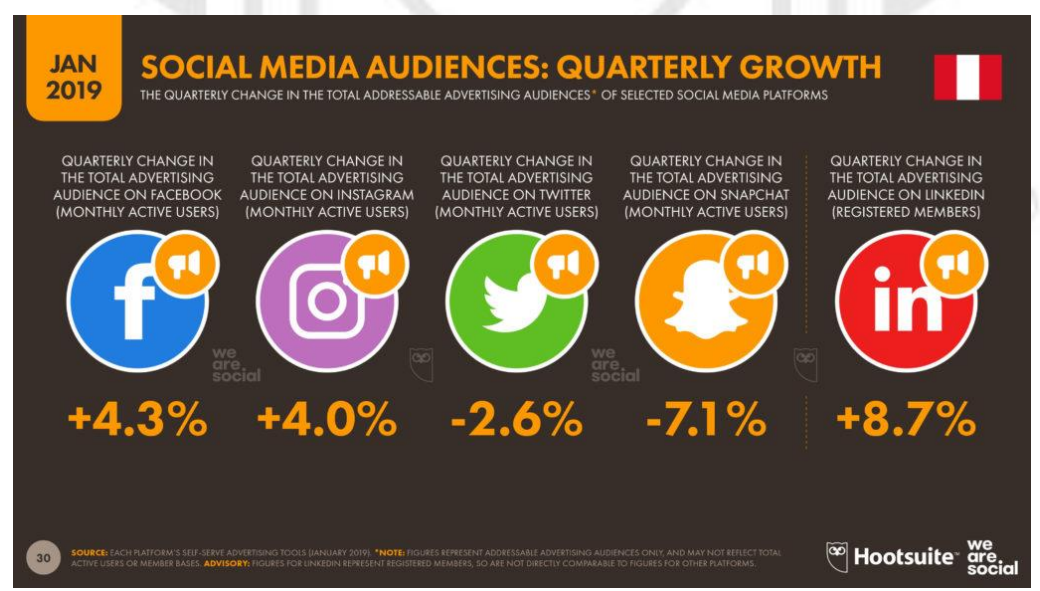

Figura 40: Social Media Audiences- Quarterly Growth. Fuente: Hootsuite - we are social 


\section{- Campaña en Youtube:}

Sustento: Youtube es una las plataformas más usadas del mundo y en el Perú su consumo es significativo. Según el estudio de Ipsos durante el año 2018 el 80\% de internautas son usuarios de Youtube y cada año ha ido creciendo. Además sería la segunda plataforma de mayor uso en nuestro público objetivo.

Acción:

- Creación de una canal de Youtube, con videos que refuercen el concepto de nuestra campaña.

- Creación de videos comerciales que aparecerán como publicidad durante la reproducción de videos de entretenimiento y otros de interés de nuestro público objetivo.

Tiempo: 3 meses (enero, febrero y marzo)

Costo total: S/. 10,140

\subsubsection{Creación web}

Creación de una página web: Proponemos en primera instancia la creación de una web exclusiva para el proyecto, la cual contendrá información acerca de nuestra identidad de marca, descripción del proyecto, galería de fotos, beneficios, contáctenos.

Además contará con un espacio donde informará a nuestro público objetivo sobre cómo puede aplicar al Fondo Mivivienda y al Bono Verde. Explicará los requisitos, los documentos presentar, bancos y financieras con las que se trabaja.

Buscaremos mejorar los motores de búsqueda SEO para tener un buen posicionamiento orgánico, esto se logrará construyendo una página web optimizada, con fotos e imágenes que tengan el peso adecuado para que la carga sea rápida. Además es importante tomar en cuenta la experiencia de usuario (UX) para facilitar la navegabilidad y no perder algún posible lead. Página web responsive: nuestra página debe estar correctamente adaptada a todos los formatos de los distintos dispositivos; computadora, celulares, tablets. 


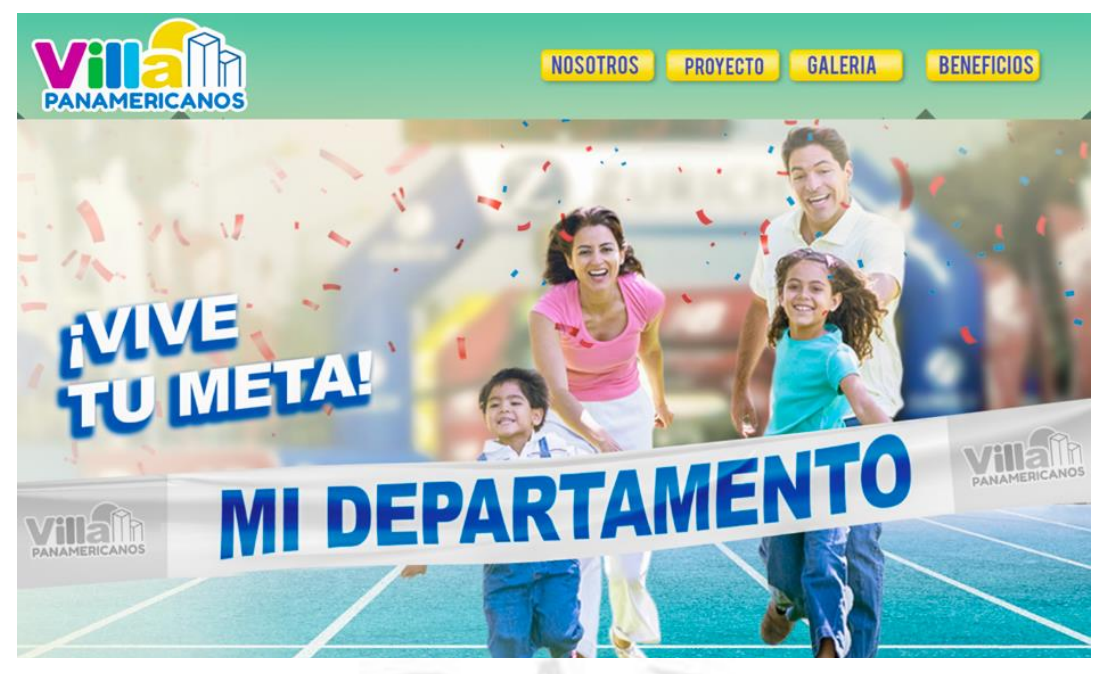

\subsubsection{Campaña en Google Adwords}

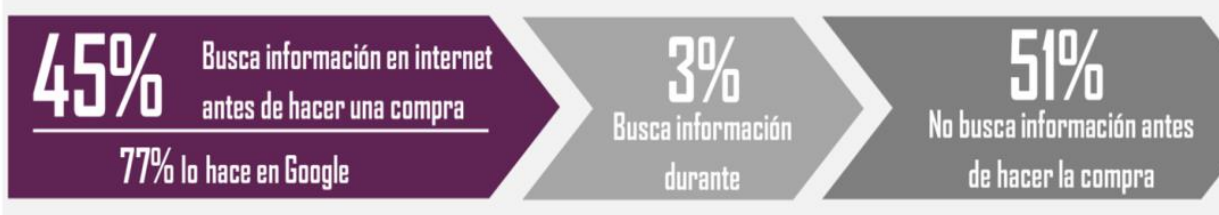

Figura 41: Hábitos de compra por Internet. Fuente: Datum

Sustento: Según Datum, el 45\% busca información en Internet para evaluar una compra y de estos el $77 \%$ hace la búsqueda por Google.

Tiempo: Los 6 meses que durarán nuestras campañas de lanzamiento y mantenimiento. Desde enero 2020 hasta junio 2020

Costo total: S/. 16900

Búsqueda de las palabras claves: Realizaremos una campaña pagada en Google Adwords haciendo un análisis de las palabras clave de búsqueda, con las palabras clave ya seleccionadas haremos diferentes anuncios. 


\begin{tabular}{|c|c|c|c|c|c|c|}
\hline$\square$ & Palabra clave (por relevancia) $\downarrow$ & Prom. búsquedas mensuales & Competencia & $\begin{array}{r}\text { Porcentaje de } \\
\text { impresiones del } \\
\text { anuncio }\end{array}$ & $\begin{array}{r}\text { Oferta de la parte } \\
\text { superior de la página } \\
\text { (intervalo bajo) }\end{array}$ & $\begin{array}{r}\text { Oferta de la parte } \\
\text { superior de la página } \\
\text { (intervalo alto) }\end{array}$ \\
\hline \multicolumn{7}{|c|}{ Palabras clave que proporcionó } \\
\hline$\square$ & bono verde & De $1 \mathrm{Ka} 10 \mathrm{~K}$ & Medio & - & PEN0.47 & PEN1.57 \\
\hline$\square$ & departamentos en villa & De 10 a 100 & Medio & - & PEN0.10 & PEN0.67 \\
\hline$\square$ & gladys tejeda & De $10 \mathrm{Ka} 100 \mathrm{k}$ & Bajo & - & - & - \\
\hline$\square$ & lotes & De 100 a $1 \mathrm{~K}$ & Bajo & - & PEN0.24 & PEN0.67 \\
\hline$\square$ & mi vivienda & De $1 \mathrm{Ka} 10 \mathrm{~K}$ & Medio & - & PEN0.40 & PEN1.18 \\
\hline$\square$ & multifamiliares villa & De 0 a 10 & - & - & - & - \\
\hline$\square$ & mivivienda verde & De $1 \mathrm{Ka} 10 \mathrm{~K}$ & Medio & - & PEN0.47 & PEN1.28 \\
\hline \multicolumn{7}{|c|}{ Ideas de palabras clave } \\
\hline$\square$ & juegos panamericanos 2019 & De $100 \mathrm{ka} 1 \mathrm{M}$ & Bajo & - & PEN0.37 & PEN1.53 \\
\hline$\square$ & panamericanos 2019 & De $10 \mathrm{Ka} 100 \mathrm{k}$ & Bajo & - & PEN0.38 & PEN4.20 \\
\hline
\end{tabular}

Ilustración 16: Ejemplo búsqueda palabras clave.

Al hacer click en nuestro anuncio, llevará a los clientes hacia una landing page, una hoja exclusiva y orientada hacia la conversión. Esta landing page contendrá los planos de los diferentes tipos de departamento para que el cliente seleccione el que prefiere llene sus datos y se les envíe la cotización e información detallada a su correo electrónico.

$\underline{\text { Pieza comunicacional: }}$

Vive en Villa Panamericanos | 3 Dormitorios, canchas multideportivas Anuncio www.villapanamericanos.pe Departamentos de 3 dormitorios, sala-comedor cocina y dos baños. Ecoamigables Áreas verdes y zonas deportivas exclusivas. Crédito Mivivienda

Ubicación - Áreas comunes - Bono Verde

Ilustración 17: Posicionamiento de la web mediante estrategia SEM

\subsubsection{Influencer}

Sustento: Los influencer se han convertido en un medio eficaz para hacer llegar mensajes publicitarios a nuestro público objetivo. Resulta más sencillo que por afinidad al target que sigue a un personaje se influencié por su estilo de vida y por lo que recomienda. Entre los beneficios más importantes está el tráfico hacia nuestra página web, awareness y llevar hacia la acción.

Personaje: 
Maricarmen Marín cuenta con 1.354.163 de seguidores en Facebook. Es una mujer peruana que genera un vínculo emocional con nuestro segmento, por tratarse de una mujer peruana progresista, emprendedora y empoderada, que tiene empatía con el público objetivo. Refleja una persona que está viviendo su meta.

Algunos datos de su performance en Facebook

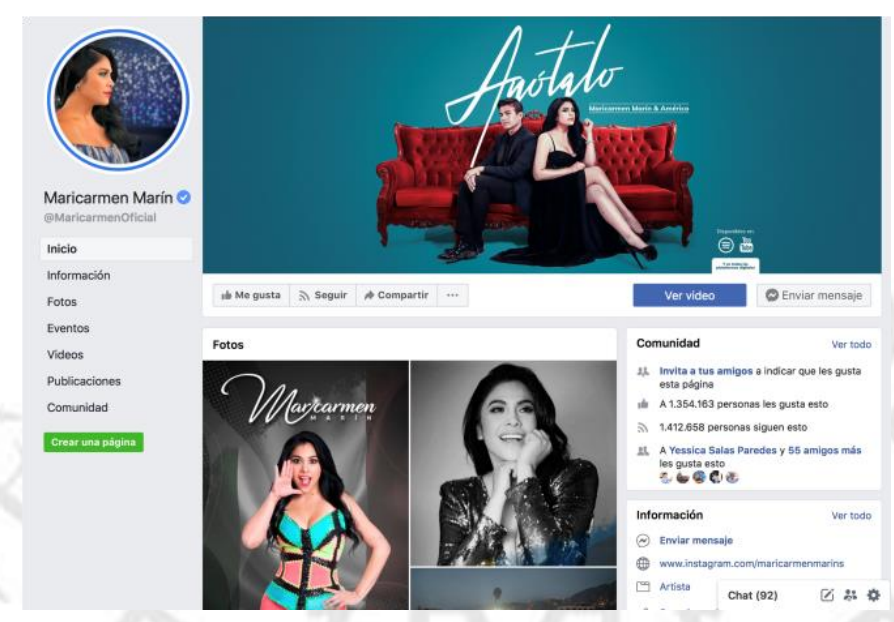

Figura 42: Interacción de Maricarmen Marín en redes sociales. Fuente: Facebook

Medio: Facebook - publicación en video

Tiempo: 2 publicaciones en Facebook por semana ( 2 semanas)

Total de anuncios: 4

Costo total: S/ 20,280

Pieza comunicacional: El influencer realizará publicaciones en su perfil de Facebook, estas estarán enfocadas en presentar a Villa Panamericanos, el video lo hará desde el lugar para mostrar las áreas más importantes y atractivas de los departamentos. Luego de mostrar estas imágenes invitará al público a hacer click para más información, este click les llevará a un landing page de nuestra página web con un formulario para dejar sus datos.

\subsubsection{Portales Web Inmobiliarios}

Sustento: Las búsquedas de departamentos por medio de Google arrojan en los primeros resultados orgánicos dos portales importantes de compra, venta y alquiler de bienes inmuebles. Estos portales son Adonde vivir y Urbania.

Formato: Anuncio 
Tiempo: Los 6 meses que durará nuestras campañas de lanzamiento y mantenimiento. Desde enero 2020 hasta junio 2020

Portales: Adonde vivir y Urbania

Pieza comunicacional: publicaciones, con toda la información importante del conjunto habitacional Villa Panamericanos, precios y fotos de todas las instalaciones.

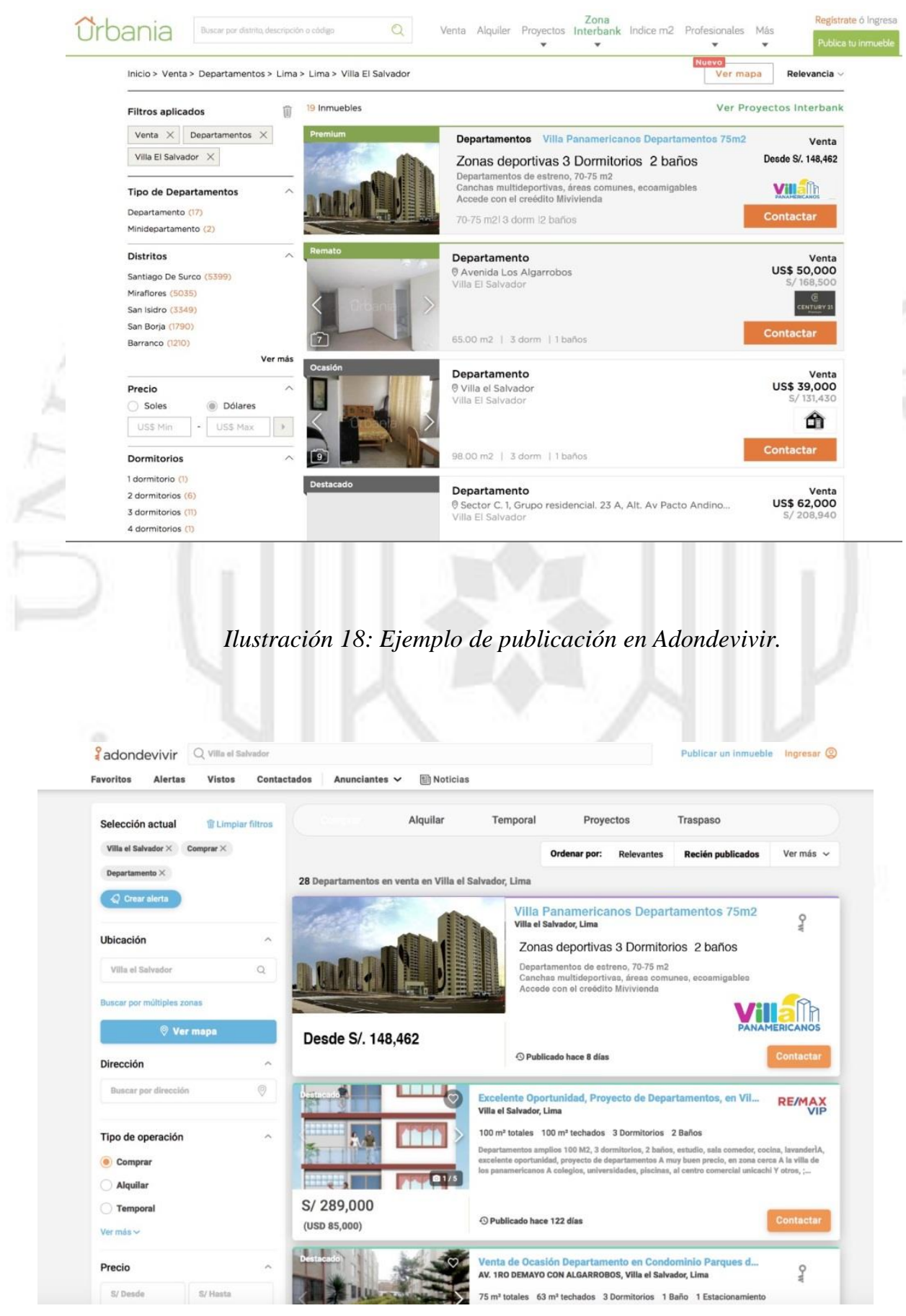

Ilustración 19: Ejemplo de publicación en Urbania. 


\subsection{Relaciones Públicas}

Sustento: Las relaciones públicas están encargadas de comunicar el mensaje de manera más creíble. La estrategia de presentar nuestra marca como noticia, hará que sea más aceptada por la opinión pública pues tendrá un matiz diferente al de una publicidad tradicional.

Sustento de medio para RP: La televisión es el medio que lidera los medios masivos, el 64\% de nuestra población lo ve diariamente y el $19 \%$ al menos una vez por semana. El tiempo de consumo de este medio es de 3 horas diarias a más y entre los programas más vistos se encuentran los informativos, liderando los noticieros de América TV.

Formato: Noticias y publirreportaje

Tiempo: 1 mes del 15 de diciembre al 15 de enero 2020 (lanzamiento)

Canales: Canal 4 América Noticias

Costo total: S/. 17,000 Soles

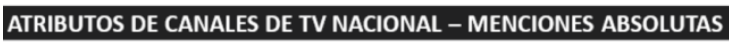

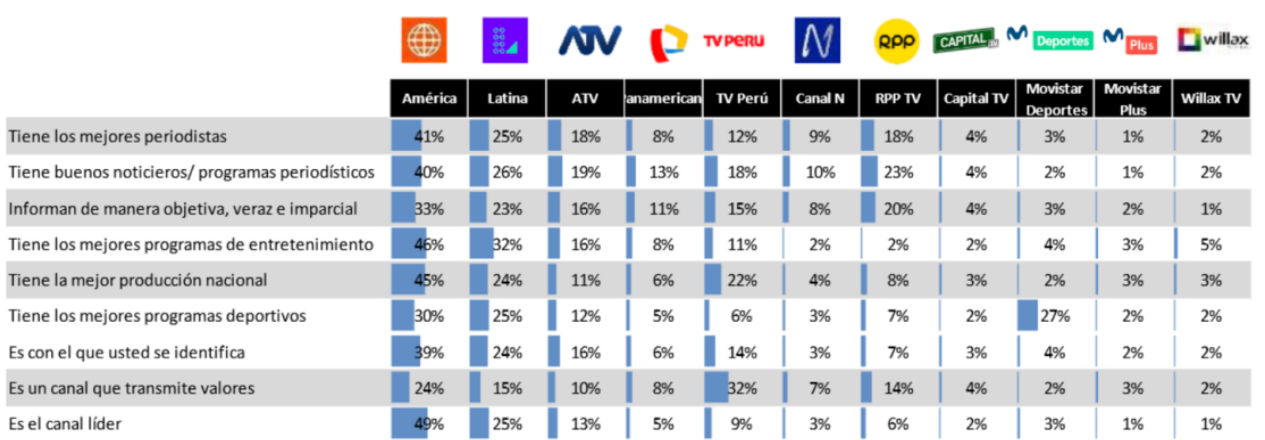

Figura 43: Atributos de canales de TV nacional. Fuente: IPSOS

Para poder medir la efectividad del cumplimiento de objetivos de cada uno de los medios planteados, tenemos mapeadas una serie de métricas que nos ayudarán a evaluar el éxito de la campaña en todas sus etapas.

\begin{tabular}{|c|c|c|c|}
\hline Medios & Conocimiento & Consideración & Acción \\
\hline PR & $\begin{array}{l}\text { Audiencia } \\
\text { Costo por mil (CPM) }\end{array}$ & $\begin{array}{l}\mathrm{N}^{\circ} \text { personas registradas } \\
\mathrm{N}^{\circ} \text { de visitas orgánicas a la } \\
\text { web }\end{array}$ & \\
\hline
\end{tabular}




\begin{tabular}{|c|c|c|c|}
\hline RADIO & $\begin{array}{l}\text { Audiencia } \\
\text { Costo por mil (CPM) }\end{array}$ & & \\
\hline $\mathrm{OOH}$ & Costo por mil (CPM) & $\begin{array}{l}\mathrm{N}^{\circ} \text { personas registradas } \\
\mathrm{N}^{\circ} \text { de visitas orgánicas a la } \\
\text { web }\end{array}$ & \\
\hline PRENSA & $\begin{array}{l}\text { Audiencia } \\
\text { Costo por mil (CPM) }\end{array}$ & $\begin{array}{l}\mathrm{N}^{\circ} \text { personas registradas } \\
\mathrm{N}^{\circ} \text { de visitas orgánicas a la } \\
\text { web }\end{array}$ & \\
\hline BTL & & $\begin{array}{l}\mathrm{N}^{\circ} \text { personas registradas } \\
\mathrm{N}^{\circ} \text { personas que solicitaron } \\
\text { información }\end{array}$ & $\begin{array}{l}\mathrm{N}^{\circ} \text { de ventas } \\
\mathrm{N}^{\circ} \text { de personas que se } \\
\text { contactan con los bancos } \\
\text { Costo por adquisición } \\
\text { (CPA) }\end{array}$ \\
\hline FАСЕВООК & $\begin{array}{l}\text { Alcance } \\
\% \text { de impresiones } \\
\text { Costo por clic (CPC) }\end{array}$ & $\begin{array}{l}\mathrm{N}^{\circ} \text { de nuevos seguidores } \\
\% \text { de comentarios positivos y } \\
\text { negativos } \\
\text { Costo por lead (CPL) } \\
\text { CTR : } \mathrm{N}^{\circ} \text { de impresiones / } \mathrm{N}^{\circ} \\
\text { de clics }\end{array}$ & $\begin{array}{l}\text { Costo por adquisición } \\
\text { (CPA) } \\
\mathrm{N}^{\circ} \text { de visitas al } \\
\text { condominio } \\
\mathrm{N}^{\circ} \text { de llamadas }\end{array}$ \\
\hline YOUTUBE & $\begin{array}{l}\% \text { de visualizaciones } \\
\text { Costo por vista (CPV) }\end{array}$ & $\begin{array}{l}\mathrm{N}^{\circ} \text { de leads que generó } \\
\text { Costo por lead (CPL) }\end{array}$ & $\begin{array}{l}\text { Costo por adquisición } \\
\text { (CPA) }\end{array}$ \\
\hline ADWORDS & $\begin{array}{l}\% \text { de impresiones } \\
\mathrm{N}^{\circ} \text { de clics } \\
\text { Costo por clic }(\mathrm{CPC})\end{array}$ & $\begin{array}{l}\mathrm{N}^{\circ} \text { de sesiones } \\
\mathrm{N}^{\circ} \text { de leads que generó } \\
\mathrm{CTR}: \mathrm{N}^{\circ} \text { de impresiones / } \mathrm{N}^{\circ} \\
\text { de clics } \\
\text { Tasa de rebote }\end{array}$ & \\
\hline $\begin{array}{l}\text { WEBS } \\
\text { ESPECIALIZADAS } \\
\text { (URBANIA Y } \\
\text { ADONDE VIVIR) }\end{array}$ & $\begin{array}{l}\mathrm{N}^{\circ} \text { de clics en avisos' } \\
\text { Tiempo de permanencia } \\
\text { en el aviso }\end{array}$ & $\begin{array}{l}\mathrm{N}^{\circ} \text { de vistas hacia la web } \\
\mathrm{N}^{\circ} \text { de leads que generó } \\
\text { Costo por lead }\end{array}$ & $\begin{array}{l}\text { Costo por adquisición } \\
\text { (CPA) } \\
\mathrm{N}^{\circ} \text { de visitas al } \\
\text { condominio } \\
\mathrm{N}^{\circ} \text { de llamadas }\end{array}$ \\
\hline INFLUENCER & $\begin{array}{l}\text { Alcance } \\
\mathrm{N}^{\circ} \text { de impresiones } \\
\mathrm{N}^{\circ} \text { de nuevos seguidores }\end{array}$ & $\begin{array}{l}\mathrm{N}^{\circ} \text { de likes en los post } \\
\mathrm{N}^{\circ} \text { de leads que generó } \\
\mathrm{N}^{\circ} \text { de leads que generó }\end{array}$ & \\
\hline WEB & $\begin{array}{l}\text { Tiempo de sesión en } \\
\text { página } \\
\% \text { de rebote } \\
\text { Webs de procedencia }\end{array}$ & $\begin{array}{l}\text { Número de leads } \\
\text { Costo por lead (CPL) }\end{array}$ & $\begin{array}{l}\text { Costo por adquisición } \\
\text { (CPA) } \\
\mathrm{N}^{\circ} \text { de visitas al } \\
\text { condominio } \\
\mathrm{N}^{\circ} \text { de llamadas }\end{array}$ \\
\hline
\end{tabular}




\section{CONCLUSIONES}

- Villa Panamericanos tiene un posicionamiento previo positivo por su rol cumplido en los Juegos Panamericanos y su presencia en los medios.

- El precio de Villa Panamericanos es un atributo valorado por el público objetivo puesto que es competitivo con otras propuestas de vivienda, siendo esta oferta más valiosa.

- $\quad$ Se debe informar y educar a nuestros clientes potenciales acerca del Fondo Mivivienda y Bono Verde.

- Los espacios deportivos y sociales son valorados por nuestro público objetivo.

- $\quad$ El respaldo de la inmobiliaria Besco es un plus importante para generar confianza y credibilidad en nuestro proyecto.

- Villa Panamericanos tiene el grado 2 de Bono Verde, atributo que dentro de poco tomará más valor puesto que las viviendas ecoamigables serán una obligación. 


\section{RECOMENDACIONES}

- Vincular los Juegos Panamericanos con nuestro concepto de campaña y piezas publicitarias es importante para mantener un plan integral.

- Aprovechar los medios de comunicación con lo que cuenta la inmobiliaria Besco porque cuentan con una cantidad importante de seguidores de nuestra segmentación.

- Mantener presencia en medios digitales en la etapa de mantenimiento será clave para seguir obteniendo leads.

- $\quad$ Es importante contar con página web y cuentas en Facebook y Youtube exclusivas de la marca Villa Panamericanos. 


\section{REFERENCIAS (Bibliografía)}

- Diario Gestión (26 de Junio del 2019). Bono Verde: Viviendas contarán con mayor tecnología ecosostenible. Recuperado el 2019 de setiembre de 20, de Diario Gestión: https://gestion.pe/economia/bono-verde-viviendas-contaran-mayor-tecnologiaecosostenible-271495-noticia/

- NTR Periodismo Crítico (30 de Marzo del 2019). Viviendas pequeñas, centro de estrés común: investigadora. Recuperado el 2019 de setiembre de 20, de Diario NTR Periodismo Crítico: http://ntrzacatecas.com/2017/03/30/viviendas-pequenas-centro-de-estres-comuninvestigadora/

- Diario Gestión (4 de Abril del 2019). Fondo Mivivienda colocó cifra récord de 1,121 créditos en marzo. Recuperado el 2019 de setiembre de 20, de Diario Gestión: https://gestion.pe/economia/bono-verde-viviendas-contaran-mayor-tecnologiaecosostenible-271495-noticia/

- Diario Gestión (2 de Abril del 2019). Fondo Mivivienda colocó cifra récord de 1,121 créditos en marzo. Recuperado el 2019 de setiembre de 20, de Diario Gestión: https://gestion.pe/economia/fondo-mivivienda-coloco-cifra-record-1-121-creditos-marzo263119-noticia/

- Diario La Prensa (1 de Agosto del 2019). Medio ambiente: ¿cómo ayuda la tecnología a tener edificaciones seguras y sostenibles?. Recuperado el 2019 de setiembre de 20, de Diario La Prensa: https://laprensa.peru.com/actualidad/noticia-medio-ambiente-comoayuda-tecnologia-tener-edificaciones-seguras-y-sostenibles-80198

- Concortv (Diciembre 2017). Estudio cuantitativo sobre consumo radial y televisivo. Recuperado el 2019 de setiembre de 20, de Concortv: http://www.concortv.gob.pe/wpcontent/uploads/2018/04/Resumen-Consumo-RadioyTV-2017.pdf

- Datum (2017). Internet en el Perú. Recuperado el 2019 de setiembre de 20, de Datum: http://www.datum.com.pe/new_web_files/files/pdf/Internet.pdf

- Construcción e Industria (13 de Agosto del 2019). Trianon: Ascensores y tableros eléctricos de última generación y eficiente postventa en la Villa de Atletas. Recuperado el 2019 de setiembre de 20, de Construcción e Industria: http://www.construccioneindustria.com/trianon-ascensores-y-tableros-electricos-deultima-generacion-y-eficiente-postventa-en-la-villa-de-atletas/ 
- RPP Noticias (27 de Noviembre del 2018). YouTube en Perú: Cuatro de cada 5 peruanos conectados a Internet mira vídeos todos los días. Recuperado el 2019 de setiembre de 20, de RPP Noticias: https://rpp.pe/tecnologia/redes-sociales/youtube-peru-cuatro-de-cada-5peruanos-conectados-a-internet-mira-videos-todos-los-dias-noticia-1165822

- IPSOS. (2018). Consumo de Medios. Lima: IPSOS Perú.

- IPSOS. (2019). Estadística Poblacional Lima Metropolitana. Lima: IPSOS Perú.

- IPSOS. (2018). Hábitos, usos y actitudes hacia Internet. Lima: IPSOS Perú.

- IPSOS. (2018). Perfiles Socieconómicos. Lima: IPSOS Perú.

- CPI Market Report (abril 2018). Audiencias Radiales 2017: Resumen Anual. Recuperado el 2019 de octubre de 17, de CP: https://www.cpi.pe/images/upload/paginaweb/archivo/26/mr_audienciasradiales_201804. pdf

- Portal RPP (29 de noviembre del 2019). RPP consolida y mantiene su liderazgo como la radio con más audiencia del Perú. Recuperado el 2019 de octubre de 17, de Portal RPP: https://rpp.pe/peru/actualidad/rpp-consolida-y-mantiene-su-liderazgo-como-la-radio-conmas-audiencia-del-peru-noticia-1166306

- Diario Perú 21 (13 de febrero del 2019). Día Mundial de la Radio: ¿Cuántas horas consumen los peruanos este medio al día?. Recuperado el 2019 de octubre de 17, de diario Perú 21: https://peru21.pe/tecnologia/dia-mundial-radio-horas-consumen-peruanosmedio-dia-459538-noticia/

- CPI Market Report (enero 2019). Lima Digital. Recuperado el 2019 de octubre de 17, de CPI: http://cpi.pe/images/upload/paginaweb/archivo/26/MR_Limadigital2018.pdf 


\section{ANEXOS}

A continuación adjuntamos el drive donde se podrá ver el desglose de:

- Material de comunicación:

https://drive.google.com/open?id=1Nen32Mj--pNQJtUIn70vDsf6cQ2JL3FQ

- Material de Investigación:

https://drive.google.com/open?id=1Q3FL-R3vTCY9ZJWkrjKYzg6SiUANc5eC

\section{Guía de Pautas de Entrevista a Profundidad}

- ¿Cuál es su nombre?

- ¿Cuál es su edad?

- ¿A qué se dedica?

- ¿Cómo está compuesta su familia? ¿Es casado? ¿A qué se dedica su esposa?

- ¿Cuántos hijos tiene? ¿De qué edades?

- ¿Dónde vive actualmente? (Casa alquilada, casa de familiar, casa propia, etc) ¿Es casa o departamento?

- ¿Qué significa para usted tener una casa propia? ¿Por qué? ¿Qué beneficios encuentra? ¿Por qué?

- ¿Qué características busca que tenga su futura vivienda? ¿Por qué es importante? ¿Cómo debe ser está característica para que cumpla sus expectativas? (metraje, distribución, precio, ambientes comunes, acabados, etc)

- ¿Ha oído hablar sobre el proyecto inmobiliario Villa de Atletas (de los Panamericanos)? ¿Qué opina de estos? ¿Por qué?

\section{PRESENTAR CONCEPTO}

- ¿Qué opina de lo que le pude decir?

- ¿Qué características le gustan?

- ¿Qué características le disgustan? ¿Cómo las mejoraría?

- ¿Qué opinión tiene acerca de que este proyecto se haya realizado exclusivamente para los Panamericanos? ¿Cómo lo beneficia o perjudica a usted? 
- Después de lo que vio, ¿qué tan interesado esta en averiguar sobre el proyecto? ¿Por qué sí? (averiguar los drivers) ¿Por qué no? (averiguar barreras y como solucionarlas)

- ¿Qué le parece que el nombre del proyecto sea Villa de Atletas? ¿Por qué? ¿A qué le remite? ¿El nombre es ideal para un proyecto inmobiliario? ¿Por qué? ¿Si no le gusta, cómo lo llamaría?

\section{CONCEPTO MOSTRADO}

\section{Condominio Villa de Atletas}

Ubicación: Avenida Mariano Pastor Sevilla Lima, Villa EL Salvador 15829 (Cruce de Av. El sol y av. Mariano Pastor Sevilla)

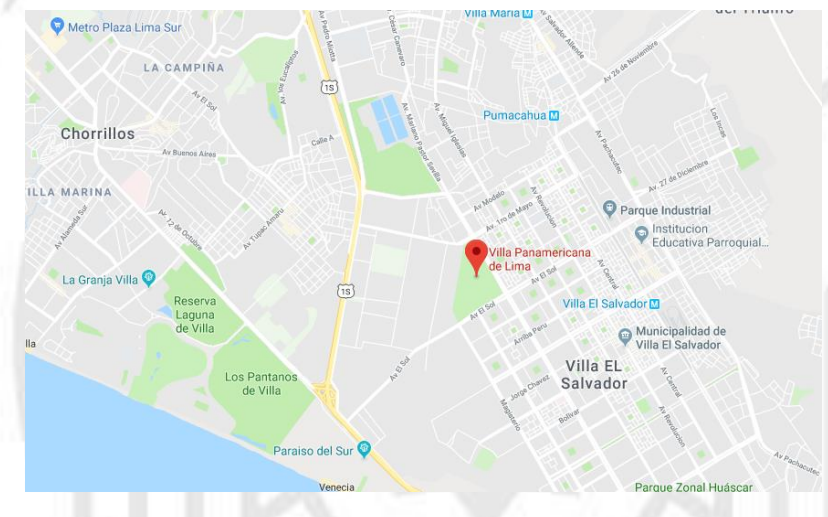

\section{Número de departamentos:}

- 1,096 departamentos divididos en siete torres (cuatro de 20 pisos y tres de 19).

- Cada piso cuenta con ocho departamentos de entre 70 y 75 metros cuadrados.

\section{Distribución:}

- 3 dormitorios, sala, comedor, cocina y 2 baños (departamento estándar)

\section{Áreas comunes:}

- 12 pequeñas edificaciones las cuales se denominarán 'Clubhouses', en donde se podrá disfrutar de actividades recreativas.

- Compuesto por 3 salas multiusos

- 1 sala de juego para jóvenes

- 1 sala de juego para niños

- 1 gimnasio 
- 2 tiendas

- Dos canchas multideportivas, una pista de ciclismo y una pista de jogging (trote) de un kilómetro de largo que bordea las torres para el fomento del deporte.

\section{Otras características:}

- Las torres construidas son ecoamigables, cumplen con la Certificación Bono Verde para contribuir con el cuidado del medio ambiente.

- Mecanismos novedosos para ahorrar en el consumo de servicios.

- Reutilización de las aguas grises que circulen por el lavatorio y ducha, luego de pasar por un tratamiento, se volverá a emplear el riego de las áreas verdes sin necesidad de usar el de la red pública)

- La infraestructura cuenta también con luminarias LED y griferías con controladores de flujos, por lo que el gasto en luz será el menor posible.

- Fácil acceso de personas con discapacidad, además, algunas de las zonas cuentan con el sistema de lectura braille.

Precios: S/186,000.00 (departamento estándar)

\section{Facilidades de pago:}

- Vendidos por Nuevo crédito Mi Vivienda

- Los departamentos cuentan con el Grado 2 de certificación por ello hay un bono adicional del $4 \%$ que se calcula al valor del financiamiento. 